Document downloaded from:

http://hdl.handle.net/10251/75189

This paper must be cited as:

Muriel-Galet, V.; Lopez-Carballo, G.; Gavara Clemente, R.; Hernández-Muñoz, P. (2014). Antimicrobial Properties of Ethylene Vinyl Alcohol/Epsilon-Polylysine Films and Their Application in Surimi Preservation. Food and Bioprocess Technology. 7(12):3548-3559. doi:10.1007/s11947-014-1363-1.

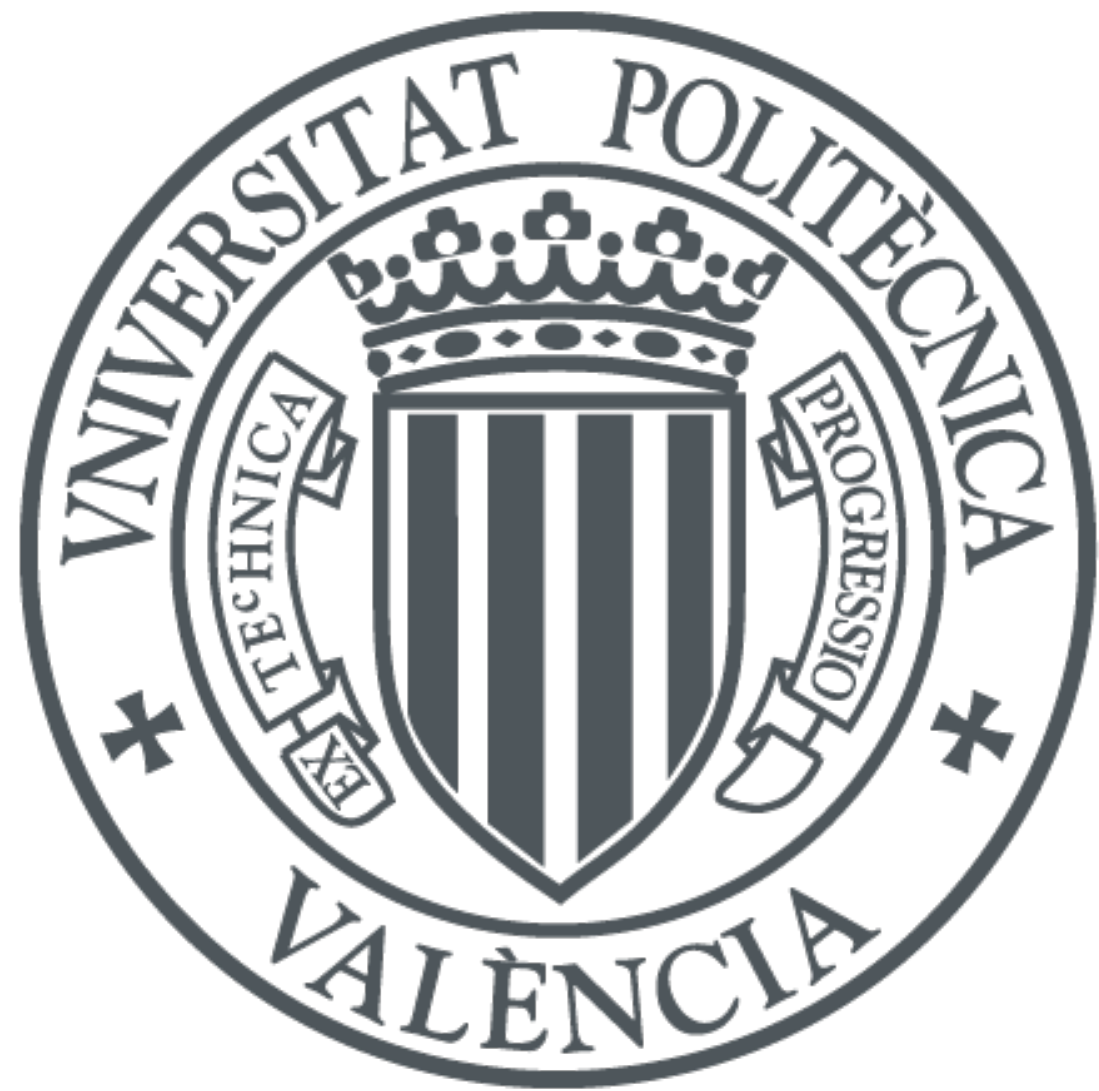

The final publication is available at

https://dx.doi.org/10.1007/s11947-014-1363-1

Copyright Springer Verlag (Germany)

Additional Information 


\title{
Antimicrobial properties of ethylene vinyl alcohol/epsilon-polylysine films and their application in surimi preservation
}

\author{
Muriel-Galet, V; López-Carballo, G; Gavara, R; Hernández-Muñoz, P* \\ Packaging Lab, Instituto de Agroquímica y Tecnología de Alimentos, IATA-CSIC, Av. \\ Agustín Escardino 7, 46980 Paterna, SPAIN, Phone: +34-963900022, Fax: +34-963636301 \\ Email: phernan@iata.csic.es
}

\begin{abstract}
Polymer films based on ethylene vinyl copolymers (EVOH) containing a 29\% (EVOH29) and a $44 \%$ molar percentage of ethylene (EVOH44), and incorporating $\varepsilon$-polylysine (EPL) at 0, 1, 5 and $10 \%$ were successfully made by casting. The optical properties and the amount of EPL released from the films to phosphate buffer at $\mathrm{pH} 7.5$ were evaluated, films showing great transparency and thoseEVOH29 copolymer releasing a greater amount of EPL. The antimicrobial properties of the resulting films were tested in vitro against different foodborne microorganisms and in vivo in surimi sticks. With regard to the antimicrobial capacity tested in vitro in liquid medium at $37{ }^{\circ} \mathrm{C}$ and $4{ }^{\circ} \mathrm{C}$ against Listeria monocytogenes and Escherichia coli over a period of $72 \mathrm{~h}$, films showed a considerable growth inhibitory effect against both pathogens, more notably against L. monocytogenes, and being EVOH29 more effective than EVOH44 films. At $37^{\circ} \mathrm{C}$ total growth inhibition was observed for EVOH 29 films incorporating $10 \%$ EPL against both microorganisms whereas the copolymer EVOH 44 did show total inhibition against $L$. monocytogenes and the growth of $E$. coli was reduced by 6.64 log units. At $4{ }^{\circ} \mathrm{C}$ no film was able to inhibit completely bacterial growth. Scanning electron microscopy micrographs showed corrugated cell surfaces with blisters and bubbles, and collapse of the cells appearing shorter and more compact after treatment with EPL. Finally, the films were successfully used to increase the shelf life of surimi sticks. The results show the films developed have great potential for active food packaging applications.
\end{abstract}

Keywords: EVOH, epsilon-polylysine; antimicrobial polymer films; L. monocytogenes; E. coli 
36

37

\section{INTRODUCTION}

Ready-to-eat products with an extended shelf life, stored at refrigeration temperatures $\left(4{ }^{\circ} \mathrm{C}\right)$ and consumed without further cooking have been implicated in various outbreaks of microbial food-borne illness. Listeria monocytogenes and Escherichia coli have been implicated in many outbreaks, most commonly due to post-processing contamination (Tzschoppe et al. 2012; Muriel-Galet et al. 2012a).

Listeriosis is a food-borne illness that affects susceptible populations, such as the young, the elderly, pregnant women and immunocompromised individuals (YOPIs). L. monocytogenes is considered a pathogen of major concern. It has a long incubation period, which makes it difficult to identify the food that is contaminated with L. monocytogenes and causes illness (Huss et al. 2000). E. coli is found in a wide variety of foods, causing food-borne disease outbreaks (Buchanan and Doyle 1997; Mead and Griffin 1998). A great number of cases can be severe and they are sometimes fatal.

Imitation crab meat (surimi) is a paste prepared from mechanically deboned, washed (bleached) and stabilized flesh of fish (FAO 2005). Surimi is one of the most promising approaches to obtain value-added food products from low-cost fishery products (Venugopal and Shahidi 1995). Surimi is used in the preparation of cooked ready-to-eat products which are sensitive to microbial contamination with diverse Gram positive and Gram negative bacteria after processing, e.g. L. monocytogenes (Miya et al. 2010). This microorganism is a serious threat to food safety in processing plants, being a very ubiquitous bacterium that can grow in many chilled food products. Proper refrigeration temperature below $4^{\circ} \mathrm{C}$, handling, preparation and service under Good Manufacturing Practices (GMP) are strategies that can prevent the crosscontamination of surimi products (Kaneko et al. 1999; Park 2014).

The increase in food-borne illness outbreaks has intensified research on antimicrobial packaging technologies (Suppakul et al. 2003), with a particular interest in the use of natural antimicrobial agents, including essential oils and their components, organic acids, enzymes, peptides, etc. Epsilon-polylysine (EPL) is a natural cationic linear homopolymer compound of 25-35 residues of L-lysine connected between the $\varepsilon$-amino and $\alpha$-carboxyl groups (Shima and Sakai 1977; Shima et al. 1984). It is produced from aerobic fermentation by Streptomyces albulus, a nonpathogenic microorganism (Hiraki et al. 2003). EPL is characterized as being edible, water soluble, stable at high temperatures and of low environmental impact because of its biodegradability. The antimicrobial activity of EPL depends on electrostatic interaction with the cell surface of microorganisms, leading to distortion of the outer membrane and producing abnormal distribution of the cytoplasm (Shima et al. 1984). EPL has an isoelectric point of 9.0, and the optimum $\mathrm{pH}$ range to exert its antimicrobial activity is between 5 and 8 . EPL is non- 
toxic to humans and has been approved as a food additive in Japan at a concentration of 1000$5000 \mathrm{ppm}$ for sliced fish or fish sushi and at a concentration of 10-500 ppm for the preservation of rice, soup and vegetables (Hiraki 1995, 2000). EPL has been classified as GRAS (Generally Recognized as Safe) by the Food and Drug Administration (FDA) (FDA 2004). In recent years, EPL has been used in a wide range of industrial applications, as a food preservative (Zinoviadou et al. 2010; Chang et al. 2010), emulsifying agent (Chang et al. 2012), etc. Information regarding the antimicrobial activity of EPL when it is incorporated into a film matrix is limited, finding studies with edible coatings (Unalan et al. 2011; Zinoviadou et al. 2010), however, no studies have been found in the bibliography regarding the development of antimicrobial films by incorporating EPL in conventional polymer matrices used in food packaging.

Ethylene-vinyl alcohol (EVOH) copolymers are approved for food contact applications and have been used as matrices for the development of active packaging systems (Muriel-Galet et al. 2012b; Muriel-Galet et al. 2012a; Muriel-Galet et al. 2013a; Lopez de Dicastillo et al. 2011; Lopez-de-Dicastillo et al. 2010; Lopez-de-Dicastillo et al. 2012). Because of their hydrophilic nature, EVOH films have a great potential to be used as carriers and release matrices of bioactive agents. These polymers can protect the agent during storage in a dry environment and trigger their activity on exposure to a humid environment, in this case created by the packaged food product (Aucejo et al. 2000).

In this context, the present study intends to show the potential of EVOH copolymers to develop antimicrobial films for food packaging applications incorporating the antimicrobial compound EPL in EVOH films containing a $29 \%$ and a $44 \%$ molar percentage of ethylene. The ability of the films to inhibit the growth of L. monocytogenes and E. coli was evaluated in vitro. Finally, the effectiveness of the films was tested in a real food, surimi sticks. This product is an ideal medium for bacterial growth because it has high water and nutrient contents and limited shelf life.

\section{MATERIALS AND METHODS}

\subsection{Materials}

Ethylene vinyl alcohol copolymer (EVOH) possessing a 29 and a $44 \%$ ethylene molar content was kindly provided by The Nippon Synthetic Chemical Company (Osaka, Japan); 1-propanol was purchased from Sigma (Madrid, Spain). EPL, from Chisso Corporation (Yokohama, Japan), was kindly provided by Goddard Research Group (Amherst, USA). Imitation crab meat (surimi) was purchased from a local market, labelled as preservative-free and containing $2.5 \mathrm{~g}$ of total fat, $12.9 \mathrm{~g}$ of total carbohydrate, and $8.4 \mathrm{~g}$ of protein. 


\subsection{Film Preparation}

EVOH films were prepared as described in a previous work (Muriel-Galet et al. 2012b). Briefly, EPL was dissolved in distilled water at 1, 5 and $10 \%$ (g/100 g dry polymer). EVOH 29 was dissolved in a 1-propanol:EPL water mixture at $80{ }^{\circ} \mathrm{C}$ and EVOH 44 in a 2:1 (v:v) 1propanol:EPL water mixture at the same temperature. The solution was stirred for 30 min using a magnetic stirrer. After that time, $5 \mathrm{~mL}$ of each film-forming solution was extended over a glass plate using an extension bar, and placed in a drying tunnel equipped with a $2500 \mathrm{~W}$ heat source for $10 \mathrm{~min}$ until it was completely dry. Films prepared without EPL were used as controls. Film thickness was measured using a Mitutoyo micrometer (Osaka, Japan) and had an average value of $15 \pm 2 \mu \mathrm{m}$. Finally, the films were stored in glass desiccators containing silica gel at $22{ }^{\circ} \mathrm{C}$ prior to use.

\subsection{Optical properties}

Film colour was measured with a Konica Minolta CM-3500d spectrophotometer (Konica Minolta Sensing Inc., Osaka, Japan) set to D65 illuminant $/ 10^{\circ}$ observer angle. The film specimen was placed on the surface of a standard white plate. The instrument's software, SpectraMagic NX, was used to acquire the colour data and to display them in the CIELAB colour space.

The parameters $L^{*}$ (black (0) to white (100)), $a^{*}$ (green $(-)$ to red $(+)$ ) and $b^{*}$ (blue (-) to yellow (+)) were obtained and the polar coordinates, the chroma $C^{*}$ and the hue angle $h^{\circ}$ were calculated. Eight measurements of each sample were taken, and three samples of each film were evaluated. All the samples were selected with the same thickness to reduce the effect of thickness on the colour parameters.

\subsection{Quantification of EPL migration from EVOH films}

The amount of EPL capable of migrating out of the polymer matrix was quantified using the bicinchoninic acid assay (BCA). A sample of $0.25 \mathrm{~g}$ of each film (control, and incorporating 1, 5 and $10 \%$ of EPL) was immersed in $10 \mathrm{~mL}$ of $\mathrm{pH} 7.5$ phosphate buffer for 24 hours at $37{ }^{\circ} \mathrm{C}$. After that time, $100 \mu \mathrm{L}$ of each sample was put in contact with the working reagent. The absorbance was measured at $562 \mathrm{~nm}$ (Kang et al. 1996; Uchida et al. 1993) using a POLARstar Omega multi-detection microplate reader (Biogen Cientifica S.L., Madrid, Spain). A standard curve of bovine serum albumin was used to calculate protein mass per film sample area. 


\subsection{Antimicrobial tests}

\subsubsection{Strains}

Gram-positive bacterium Listeria monocytogenes CECT 934 (ATTCC 19114) and Gramnegative bacterium Escherichia coli CECT 434 (ATCC 25922) were selected because of their relevance to imitation crabmeat (surimi). Strains were obtained from the Spanish Type Culture Collection (CECT Valencia, Spain) and stored in Tryptone Soy Broth (TSB), purchased from Scharlab (Barcelona, Spain), with $20 \%$ glycerol at $-80{ }^{\circ} \mathrm{C}$ until needed. For experimental use, the stock cultures were maintained by regular subculture on slants of Tryptone Soy Agar (TSA) from Scharlab (Barcelona, Spain) at $4{ }^{\circ} \mathrm{C}$ and transferred monthly. Before each experiment a loopful of each strain was transferred to $10 \mathrm{~mL}$ of TSB and incubated at $37^{\circ} \mathrm{C}$ for $18 \mathrm{~h}$ to obtain early-stationary phase cells.

\subsubsection{Antimicrobial activity of EPL against L. monocytogenes and E. coli}

The antimicrobial activity of EPL was tested in sterile TSB to study the minimum inhibitory concentration (MIC) and the minimum bactericidal concentration (MBC) against $L$. monocytogenes and E. coli. To do so, serial dilutions of $1000 \mathrm{ppm}$ of EPL in peptone water were made. Previously, $100 \mu \mathrm{L}$ of cell cultures of each microorganism in stationary phase, with an optical density of 0.9 at $595 \mathrm{~nm}$, was diluted in $10 \mathrm{~mL}$ of TSB and incubated at $37{ }^{\circ} \mathrm{C}$ until exponential phase, corresponding to an optical density of 0.2 at $595 \mathrm{~nm}\left(10^{5} \mathrm{CFU} / \mathrm{mL}\right)$. Optical density was measured with a UV-Vis spectrophotometer (Agilent 8453 Spectroscopy System) using TSB as blank. $100 \mu \mathrm{L}$ of each microorganism in exponential phase was inoculated in each test tube with $100 \mu \mathrm{L}$ of EPL solution at concentrations ranging between 10 and $150 \mu \mathrm{g} / \mathrm{mL}$. Tubes with $100 \mu \mathrm{L}$ of peptone water were used as control. Turbidity at $595 \mathrm{~nm}$ was determined after 24 and $72 \mathrm{~h}$ (M100-S18 2008). The lowest EPL concentration that inhibited the pathogen microorganisms was recorded as the MIC. The MBC was the lowest concentration at which bacteria failed to grow in TSB and were not culturable after spreading $100 \mu \mathrm{L}$ onto $15 \mathrm{~mL}$ of culture medium TSA. Tests were performed in triplicate.

\subsubsection{Antimicrobial activity of EVOH films containing EPL against L. monocytogenes and E.} $\underline{\text { coli }}$

Antimicrobial activity of EVOH films with EPL was tested in liquid media at $37{ }^{\circ} \mathrm{C}$. This temperature was chosen because it is the optimal growth temperature and it is a standard method to evaluate the activity of antimicrobial films. For this purpose, $0.25 \mathrm{~g}$ of EVOH films cut into pieces measuring $1.5 \mathrm{~cm}^{2}$ (EVOH 29 and EVOH 44), without and with 1, 5 and 10\% EPL, was added to a glass tube containing $10 \mathrm{~mL}$ of TSB. Then $100 \mu \mathrm{L}$ of microorganism in exponential phase was transferred to the samples and incubated at $37{ }^{\circ} \mathrm{C}$ for $24 \mathrm{~h}$. Depending on the 
173 turbidity of the tubes, serial dilutions with peptone water were made and plated in Petri dishes with $15 \mathrm{~mL}$ of TSA culture medium. Colonies were counted after incubation at $37{ }^{\circ} \mathrm{C}$ for $24 \mathrm{~h}$.

\subsubsection{Scanning electron microscopy observations}

After the microorganisms had been in contact with EVOH films at $37{ }^{\circ} \mathrm{C}$ for $24 \mathrm{~h}$ as described above, the samples were centrifuged and resuspended twice in saline solution $(0.8 \% \mathrm{NaCl})$. The suspension was filtered on a $0.2 \mathrm{~mm}$ Nuclepore Track-Etch Membrane (Whatman, UK) and the membranes were dehydrated in graded alcohols $(30 \%, 50 \%, 70 \%, 90 \%$ and $100 \%)$. SEM observation of L. monocytogenes and E. coli was carried out, working at 5-10 kV (HITACHI S 4100)

\subsubsection{Antimicrobial activity of EVOH films containing EPL over time}

Next, the effect of EVOH with EPL films on the growth of L. monocytogenes and E. coli over time was studied. Bacterial growth experiments were performed at two temperatures, $37^{\circ} \mathrm{C}$ and $4{ }^{\circ} \mathrm{C}$, and they lasted 72 hours. For this purpose, $100 \mu \mathrm{L}$ of exponential phase microorganism was inoculated into tubes with $10 \mathrm{~mL}$ of TSB. $0.25 \mathrm{~g}$ of EVOH films cut into pieces measuring $1.5 \mathrm{~cm}^{2}$ (EVOH 29 and EVOH 44), without and with 1, 5, and 10\% EPL, was added to each tube and incubated at the corresponding temperature. Aliquots containing $100 \mu \mathrm{L}$ were removed from the solution at $0,1,3,6,24,48$ and 72 hours and serial dilutions with peptone water were made and plated in Petri dishes with $15 \mathrm{~mL}$ of TSA culture medium. Colonies were counted after incubation at $37{ }^{\circ} \mathrm{C}$ for $24 \mathrm{~h}$. Experiments were performed in triplicate.

\subsubsection{Antimicrobial activity of EVOH films incorporating EPL in surimi microbiota}

Refrigerated surimi sticks were purchased in a local market. Individual pieces (ca. $25 \mathrm{~g}$ ) were wrapped with EVOH 29 and EVOH 44 films containing 10\% of EPL. Samples without film, and samples wrapped with EVOH 29 and EVOH 44 films without EPL were prepared as controls. All the surfaces of the food were in contact with the films. Samples were stored at $4{ }^{\circ} \mathrm{C}$ for 6 days.

The effect on the surimi microbiota of being covered with film was evaluated on days 1,3 and 6. For this purpose, at appropriate times, surimi samples were transferred aseptically in a sterile stomacher bag, diluted with $25 \mathrm{~mL}$ of peptone water (Scharlab, Barcelona, Spain) for $3 \mathrm{~min}$ using a Stomacher (IUL S.L., Barcelona). Serial dilutions in the same saline solution were plated on specific media (Scharlab, Barcelona, Spain) under the following culture conditions: a) Violet Red Bile Glucose agar (VRBG) for total enterobacteria, incubated at $37{ }^{\circ} \mathrm{C}$ for $48 \mathrm{~h}$; b) Man, Rogosa and Sharpe agar (MRS) for lactic acid bacteria, incubated at $25^{\circ} \mathrm{C}$ for 5 days; c) Nutrient Agar (NA) for total aerobic bacteria, incubated at $37{ }^{\circ} \mathrm{C}$ for $48 \mathrm{~h}$; d) Nutrient Agar 
206 (NA) for total aerobic psychrotrophic bacteria, incubated at $10{ }^{\circ} \mathrm{C}$ for 10 days; e) Plate Count 207 Agar (PCA) for total aerobic count, incubated at $30{ }^{\circ} \mathrm{C}$ for $48 \mathrm{~h}$; f) King B agar for 208 Pseudomonas, incubated at $30^{\circ} \mathrm{C}$ for $48 \mathrm{~h}$. The counts were performed in triplicate.

209 2.5.7. Antimicrobial activity of EVOH films incorporating EPL on surimi inoculated with $L$. $210 \quad$ monocytogenes and E. coli

211 For this study, surimi sticks were inoculated with a diluted overnight culture $\left(100 \mu \mathrm{L} ; 10^{5}\right.$ $212 \mathrm{CFU} / \mathrm{mL}$ ) of L. monocytogenes and E. coli. The inoculums were separately dispersed on the 213 food surface with a sterile pipette. The subsequent procedure was similar to that described in the 214 previous section. The antimicrobial activity of the films against inoculated microorganisms was 215 evaluated on days 1, 3 and 6, as mentioned above. For this purpose, serial dilutions were made 216 and plated on selective media: Palcam Listeria Selective Agar for L. monocytogenes (Scharlab, 217 Barcelona, Spain) and Brilliant Green agar for E. coli. Colonies were counted after incubation at $21837^{\circ} \mathrm{C}$ for $24 \mathrm{~h}$. Samples were analysed in triplicate.

\section{$219 \quad$ 2.6. Statistical analysis}

220 One-way analyses of variance were carried out using the SPSS ${ }^{\circledR} 189$ computer program (SPSS 221 Inc., Chicago, IL, USA). Differences in pairs of mean values were evaluated by the Tukey test 222 for a confidence interval of $95 \%$. Data are represented as mean \pm standard deviation.

\section{RESULTS AND DISCUSSION}

In this work, EPL was successfully incorporated in EVOH films (EVOH 29 and EVOH 44) at 1,

2265 and $10 \%$ and the films, produced by casting, were transparent and without discontinuities, 227 presenting a thickness of approximately $15 \pm 2 \mu \mathrm{m}$.

\section{3.1. Optical properties}

229 Colour coordinates $\mathrm{L}^{*}, \mathrm{a}^{*}, \mathrm{~b}^{*}$, chroma $\left(\mathrm{C}^{*}\right)$ and hue $\left(\mathrm{h}^{\circ}\right)$ of films made from EVOH 29 and 230 EVOH 44 without and with 1, 5 and 10\% of EPL are given in Table 1. Incorporation of the 231 antimicrobial agent did not affect the luminosity of either of the copolymer films, since in all the samples the $\mathrm{L}^{*}$ values are similar to those obtained for the control (Table 1), without significant 233 differences. Colour coordinates $\mathrm{a}^{*}$ and $\mathrm{b}^{*}$ presented values close to -1 and 1 respectively for 234 both films, EVOH 29 and EVOH 44. The addition of EPL increased the absolute value of both 235 coordinates when EPL was added at the higher concentration, with significant differences 236 appearing between samples and control. Colour intensity given by the chroma $\left(\mathrm{C}^{*}\right)$ parameter increased with the concentration of EPL but films maintained their original light yellow-green 
240

241

242

tone given by the hue $\left(\mathrm{h}^{\circ}\right)$ parameter. Significant differences were only found in $\mathrm{C}^{*}$ for films containing 10\% EPL were compared with control films.

\subsection{Quantification of EPL migration from EVOH films}

The amount of protein that had migrated after $24 \mathrm{~h}$ at $37{ }^{\circ} \mathrm{C}$ in $\mathrm{pH} 7.5$ phosphate buffer was determined with the BCA assay. Table 2 shows the results obtained for EVOH 29 and EVOH 44 films incorporating 1, 5 and 10\% EPL. The value of the protein released into the phosphate buffer increased with the concentration of EPL in the films, being $47.43 \mu \mathrm{g} / \mathrm{mL}$ for $1 \%$ and $95.90 \mu \mathrm{g} / \mathrm{mL}$ for $10 \%$ with $\mathrm{EVOH} 29$. For $\mathrm{EVOH} 44$, the amount that migrated was 42.87 $\mu \mathrm{g} / \mathrm{mL}$ for films with $1 \% \mathrm{EPL}$ and $71.46 \mu \mathrm{g} / \mathrm{mL}$ for films with $10 \% \mathrm{EPL}$. It can be observed that films with a higher percentage of ethylene retained a greater amount of EPL. This behaviour has been observed previously for the antimicrobial LAE (Muriel-Galet et al. 2013b). The lower swelling achieved for EVOH 44 films in liquid media could explain the results obtained.

\subsection{Antimicrobial activity of EPL against L. monocytogenes and E. coli}

The antimicrobial activity of EPL was tested against $L$. monocytogenes and $E$. coli. The growth of L. monocytogenes and E. coli was inhibited by EPL at concentrations in TSB of 23 and 40 ppm, respectively. In another study, a lower MIC value was reported for L. monocytogenes (Brandt et al. 2010), but according to various authors EPL inhibits the growth of both Grampositive and Gram-negative bacteria and the minimum inhibitory concentration is below 100 ppm (Hiraki et al. 2003; Shima et al. 1984). Differences in methodology, media composition and bacterial strains may be responsible for the different values. The MBC values obtained were 70 and 90 ppm for L. monocytogenes and E. coli, respectively. The antimicrobial effect of EPL is attributed to electrostatic absorption onto the cell surface of the microorganism, where it interacts with the bacterial membranes (Ho et al. 2000). The difference in the MIC values between the Gram-positive and Gram-negative bacteria might derive from different cell surface conditions of the bacteria tested. Gram-negative microorganisms have an increased defence system and are less susceptible to antibacterial action than Gram-positive microorganisms. They have an outer membrane surrounding the cell wall that restricts the diffusion of compounds (Adams and Moss 2008).

\subsection{Antimicrobial activity of EVOH films containing EPL against $L$. monocytogenes and} E. coli

The antimicrobial activity of the EVOH films was tested against L. monocytogenes and E. coli. Tables 3 and 4 present the results for EVOH 29 and EVOH 44 films, respectively. The EVOH 29 films with $1 \%$ EPL produced a $4.09 \log$ reduction in the growth of L. monocytogenes and a 
$2.74 \log$ reduction for $E$. coli. Films with 5\% EPL produced a reduction of $6.09 \log$ against $L$. monocytogenes and $5.58 \mathrm{log}$ for E. coli, and films with 10\% EPL produced total inhibition against both microorganisms tested. As can be seen in Table 4 (EVOH 44 films), the viable counts for all microorganisms decreased with 1\% EPL, being 1.39 for L. monocytogenes and 0.52 for E. coli. Films containing 5\% EPL caused a growth reduction of $4.97 \log$ against $L$. monocytogenes and 3.94 for E. coli, and EVOH 44 films with 10\% EPL produced total inhibition only against $L$. monocytogenes and produced a $6.64 \log$ reduction in the growth of $E$. coli.

The results show that the antimicrobial activity was greater for EVOH 29 than for EVOH 44 films, and E. coli appears to be less susceptible to the antimicrobial effect of EPL. This lower antimicrobial effect of EVOH 44 films was expected; as noted in the migration assay of EPL carried out with BCA, the amount of EPL that migrated from EVOH 44 films was always lower than the amount that migrated from EVOH 29 films.

\subsection{Scanning electron microscopy observations}

SEM was performed on bacteria exposed to EVOH 29 and EVOH 44 films with 10\% EPL, to study the morphological changes resulting in the membrane structure. The micrographs show that bacteria exposed to the antimicrobial films displayed considerable morphological alterations in comparison with control bacteria. Figs. 1A and $1 \mathrm{C}$ show micrographs of control $L$. monocytogenes and E. coli, respectively, with bacteria presenting a smooth surface and characteristic rod shape. Figs. 1B and 1D show bacteria that have been exposed to the antimicrobial films, and it can be observed that the bacteria are seriously damaged, presenting an irregular rough surface with blisters and bubbles and the collapse of the bacteria compared with the control. In the case of L. monocytogenes the alterations are more obvious.

The images reveal that EPL leads to dramatic changes in the cell membrane. This hypothesis is consistent with the results obtained by Shima et al. (1984), which show that the mechanism of action of EPL on bacterial growth is the electrostatic adsorption onto the cell surface of microorganisms, increasing the membrane permeability and causing an abnormal distribution of cytoplasm.

\subsection{Antimicrobial activity of EVOH films containing EPL over time}

\subsubsection{Bacterial growth studies at $37^{\circ} \mathrm{C}$}

Fig. 2 shows the growth curves at $37^{\circ} \mathrm{C}$ of L. monocytogenes and E. coli exposed to EVOH 29 films containing 1, 5 and 10\% EPL for a period of 72 hours. Fig. 3 shows the results obtained with $\mathrm{EVOH} 44$. As can be seen in both figures, in the absence of antimicrobial films the bacteria 
306

307

308

309

310

311

312

313

314

315

316

317

318

319

320

321

322

323

324

325

326

327

328

329

330

331

332

333

334

335

336

337

338

339

grow to values of $9 \log$ at $37{ }^{\circ} \mathrm{C}$; owing to temperature conditions and presence of nutrients in the liquid media, the bacteria exhibited optimal growth. Fig. 2A shows that the antimicrobial activity of EVOH 29 films against L. monocytogenes increased with the concentration of EPL in the film. Films with 1\% EPL presented 3 reductions after 3 hours in contact with the bacteria, maintaining these values throughout the 72-hour period studied. EVOH 29 films with 5 and $10 \%$ EPL produced a more rapid decrease in bacterial growth at short times. After 1 hour these films caused reductions of 1.84 and $2.89 \log$ compared with the control, and the maximum inhibition degree was reached after 6 hours. Films containing 5\% EPL produced a $6 \log$ reduction and films with 10\% EPL caused total inhibition, and these values remained constant until the end of the experiment.

Antimicrobial activity of EVOH 29 films against E. coli over a 72-hour exposure period is given in Fig. 2B; for films with 1\% EPL the inhibition was $2.5 \log$ after 6 hours and this value was maintained until the end of the experiment. After 1 hour, films with 5 and 10\% EPL produced reductions of $1.5 \mathrm{log}$ and $2.5 \mathrm{log}$, respectively, in comparison with the control. Films with 5 and 10\% EPL also reached the maximum inhibition degree after 6 hours of being in contact with the bacteria, and this value remained constant, with 3 log reductions for films with $5 \%$ EPL and total inhibition for films with10\% EPL.

Figs. 3A and 3B show the results obtained when working with EVOH 44 instead of EVOH 29 against L. monocytogenes and E. coli, respectively. EVOH 44 films with $1 \%$ EPL showed a 2 $\log$ reduction after 3 hours in contact with L. monocytogenes, maintaining these values throughout the period of time studied. Films with 5 and 10\% EPL reached the maximum inhibition degree after 6 hours, producing a $5 \log$ reduction when 5\% EPL was incorporated and total inhibition with $10 \%$ EPL. These results were maintained until the end of the experiment.

Fig. 3B shows the growth curve of EVOH 44 films against E. coli. No inhibition was observed with $1 \%$ EPL. The maximum inhibition degree achieved for films with 5\% EPL was 4 log reductions, and films with $10 \%$ EPL produced a reduction of $7 \mathrm{log}$. As mentioned above, the antimicrobial activity against Gram-negative bacteria was lower and total inhibition was only observed with EVOH 29 films incorporating 10\% EPL. EVOH 29 proved to be more effective than EVOH 44, releasing EPL to the media and then inhibiting bacterial growth.

\subsubsection{Bacteria growth studies at $4{ }^{\circ} \mathrm{C}$}

Bacterial growth studies were also carried out at a temperature of $4{ }^{\circ} \mathrm{C}$ to test the effectiveness of the films at refrigeration temperatures in order to simulate storage conditions in the 
consumer's refrigerator. The antimicrobial activity of EVOH 29 and EVOH 44 films against $L$. monocytogenes and E. coli at $4{ }^{\circ} \mathrm{C}$ overtime is shown in Figs. 5 and 6 for each copolymer. L. monocytogenes is a psychrotrophic pathogen whose ability to survive and multiply at low temperatures is demonstrated in Figs. 4A and 5A. As can be observed, bacteria reached values of $7.5 \mathrm{log}$ after 72 hours of exposure to control films in liquid media. In contrast, refrigeration temperature significantly reduced the growth of E. coli. As can be seen in Figs. 4B and 5B, the control sample maintained bacterial counts around $6 \log$ throughout the experiment. Films with 1\% EPL showed a reduction of ca. $2 \log$ and $1.5 \log$ for EVOH 29 and EVOH 44, respectively, against L. monocytogenes compared to the control. However, no inhibition was observed against E. coli, which may be due to slow release of EPL to the medium, being below the minimum inhibitory concentration value. Considering that the amount of protein migrated from films with $1 \%$ EPL in phosphate buffer at $37^{\circ} \mathrm{C}$ for $24 \mathrm{~h}$ is $47.43 \mu \mathrm{g} / \mathrm{mL}$ and $42.87 \mu \mathrm{g} / \mathrm{mL}$ for EVOH 29 and $\mathrm{EVOH} 44$, respectively, and taking into account that in the current experiment the release temperature is $4{ }^{\circ} \mathrm{C}$, it can be expected that the release of the antimicrobial would occur more slowly and the films would have less effectiveness. Furthermore, films incorporating a greater amount of EPL were not able to inhibit completely the growth of all the microorganisms tested. Thus, EVOH 29 and EVOH 44 films with 10\% EPL gave similar reduction values against $L$. monocytogenes and E. coli: reductions of $5.5 \log$ and $4.8 \log$ against L. monocytogenes were observed with EVOH 29 and EVOH 44, respectively, and $4 \log$ and $3.5 \log$ against E. coli.

It can be concluded from this experiment that the greatest bacterial inhibition was achieved at $37^{\circ} \mathrm{C}$, and films made from copolymers with lower ethylene content were more effective. However, when working with a refrigeration temperature of $4{ }^{\circ} \mathrm{C}$, differences in bacterial inhibition caused by both copolymers were less acute. Moreover, a slower release of EPL is expected at $4{ }^{\circ} \mathrm{C}$, which results in a limited concentration of antimicrobial in the medium, and thus a decrease in the effectiveness of the films.

\subsection{Antimicrobial activity of EVOH films containing EPL on surimi microbiota}

Once the antimicrobial effectiveness of the EVOH films had been assessed at refrigeration temperatures, a new study with real food was carried out. EVOH 29 and 44 films with 10\% EPL were chosen because these films presented great antimicrobial activity. Surimi sticks were individually wrapped with these films and stored at $4{ }^{\circ} \mathrm{C}$ for 6 days. Samples without film and samples wrapped with film without EPL were prepared as controls. The samples were subjected to microbiological analysis on days 1,3 and 6 of refrigerated storage. The results of microbiological counts of the surimi samples are shown in Table 5. It must be pointed out that 
374 no differences were found between unwrapped samples and samples wrapped with film without 375 EPL (data not shown).

376 On the first day of storage no growth of Enterobacteriaceae, lactic acid bacteria, psychrotrophic 377 bacteria, total aerobic count and Pseudomonas bacteria was observed in any sample (data not 378 shown), and no growth of Enterobacteriaceae was detected during the extended refrigerated 379 storage period studied. No growth of these bacteria is considered as an index of fish quality, 380 which is related to storage in ice, washing and evisceration (Zambuchini et al. 2008). These 381 results confirm that the surimi samples were made under Good Manufacturing Practice (GMP), 382 ensuring the quality of the products.

383 Lactic acid bacteria are commonly found in seafood products, and bacterial counts tend to 384 increase during extended refrigerated storage. As can be seen in Table 3, lactic acid bacteria 385 were found in the control sample after three days of refrigerated storage. EVOH films 386 containing 10\% EPL were capable of inhibiting growth of lactic acid bacteria in surimi sticks 387 during the period of time monitored.

388 Psychrotrophic bacteria are able to grow at refrigeration temperatures and responsible for the 389 aerobic spoilage of fish stored at refrigeration (Gunlu and Koyun 2013), and in this experiment 390 their proliferation was observed after the third day of storage Bacterial growth was also 391 observed for samples wrapped with active films: samples wrapped with EVOH 29 incorporating $39210 \%$ EPL presented a $1.45 \log$ inhibition at the third day and a $2.16 \log$ inhibition at the end of 393 storage compared with the control; when wrapped with EVOH 44, a 1.07 log reduction was 394 achieved at the third day of storage and a $1.71 \log$ reduction at the end of the storage period.

395 Total aerobic bacterial counts appeared in the control samples at the third day of storage (2.34 $396 \log$ ) and the aerobic population increased by ca. $1 \log$ at the end of the storage period. A 397 bactericidal effect was observed when surimi sticks were wrapped with EVOH 29 containing $39810 \%$ EPL during the storage time, whereas when EVOH 44 films were used microbial aerobic 399 bacterial growth was observed at the $6^{\text {th }}$ day of storage. With regard to Pseudomonas 400 proliferation in the surimi samples, Table 3 shows that bacterial growth was detected in control 401 samples on the third day of storage. EVOH 29 films with 10\% EPL exerted total inhibition on 402 day 3, whereas a $0.68 \log$ reduction was achieved with EVOH 44 compared with the control. On 403 day 6 of storage, $1.43 \log$ and $1.00 \log$ reductions were found with EVOH 29 and EVOH 44 404 with 10\% EPL, respectively, compared with the control.

405 It has also been demonstrated in previous studies that count between $2.00 \log$ and $4.00 \log$ were 406 found in total aerobic plate and total psychrophilic bacteria (Coton et al. 2011; Singh and 407 Balange 2005). 
408 It is worth pointing out that no growth of yeast and moulds was observed in any sample during

409 the storage period.

410 It can be concluded from this experiment that the active films developed provide inhibition of 411 lactic acid bacteria and total aerobic count, whereas the psychrotrophic and Pseudomonas 412 counts decreased with respect to the control by the end of storage at $4{ }^{\circ} \mathrm{C}$, when the concentration of the agent on the surimi surface is expected to be higher. monocytogenes and $E$. coli

417 Surimi sticks were surface inoculated with L. monocytogenes and E. coli, wrapped with EVOH 41829 and EVOH 44 films with 10\% EPL, and stored for 6 days at $4{ }^{\circ} \mathrm{C}$. Samples without film and 419 samples wrapped with EVOH 29 and EVOH 44 films without EPL were prepared as controls. 420 With regard to bacterial growth in control samples and in samples wrapped with EVOH with 421 EPL, no significant differences were found. Fig. 6 shows the inhibitory effect of EVOH 29 with $42210 \%$ EPL on L. monocytogenes: after 1 day of storage, a reduction of $1.76 \log$ was observed; 423 this value was maintained until the $3^{\text {rd }}$ day of storage and increased to 2.76 log reductions at the 424 end of the storage period. Regarding the samples contaminated with E. coli, the reduction was 425 ca. 1 log during the entire storage time.

426 Fig. 7 shows the inhibitory effect of EVOH 44 with 10\% EPL against L. monocytogenes and E. 427 coli. L. monocytogenes was reduced by ca. 1 log during the entire storage period. On the other 428 hand, E. coli reduction increased at the end of storage, on the $6^{\text {th }}$ day of storage. The total food429 borne bacteria counts of surimi wrapped with the active samples showed a significant decrease 430 in comparison with the control sample.

431

432 Comparing the results obtained above with the in vitro test with TSB, it can be observed that a 433 higher concentration of EPL would be necessary to produce total inhibition against $L$. 434 monocytogenes and E. coli. The antimicrobial activity of the films was probably reduced 435 because of an interaction of the antimicrobial agent with some components of the food matrix, 436 reducing its availability to kill bacteria. Moreover, the kinetics of release and the amount of EPL 437 released to the media may change when assays are made with a solid food instead of a liquid 438 medium. This behaviour has also been reported in previous works. Geornaras et al. (2007) 439 demonstrated that the antimicrobial activity of epsilon-polylysine decreased against $L$. 440 monocytogenes when was tested in six food products compared with the results obtained in vitro 441 assays carried out in broth liquid media. The authors also showed that the antimicrobial effect of 
442 active films on surimi products was higher against L. monocytogenes than against E. coli, as it 443 has been shown throughout this work.

444 The direct addition of antimicrobial agents into surimi sticks was also studied by other authors 445 (Li et al. 2012; Ting et al. 1999). Direct incorporation of the antimicrobial into the food 446 produces an immediate reduction of bacterial populations but this may not prevent the recovery 447 of injured cells or the growth of cells that were not destroyed by direct addition if residues of 448 the antimicrobial are rapidly depleted (Chi-Zhang et al. 2004). Therefore, antimicrobial active 449 films are an excellent technology to extend food shelf-life, providing a continuous antimicrobial 450 effect on the food during extended exposure.

451 An inadequate consumer knowledge on how to store ready-to-eat food at home, at the right 452 refrigerated temperature, has led to higher risks of L. monocytogenes growth (Gambarin et al. 453 2012). L. monocytogenes and E. coli are pathogens commonly detected in ready-to-eat products 454 because of their wide distribution in food factories, especially affecting interior surfaces of 455 equipment that are complicated to clean, water and utensils. Thus the chances of surimi 456 recontamination with these food-borne bacteria after post-process procedures are very high. 457 Low temperature control during processing, shipment and storage may not be sufficient to 458 control bacterial growth adequately. Therefore, to increase food safety and extend the shelf life 459 of ready-to-eat surimi products during storage time, it is necessary to complement the post460 processing action to control the growth of pathogens L. monocytogenes and E. coli.

461

462

\section{CONCLUSIONS}

463

464 Films made from EVOH 29 and EVOH 44 copolymers incorporating several amounts of EPL 465 were successfully developed by casting, being continuous and transparent. Their optical 466 properties represented changes with respect to the control samples only at the higher 467 concentration of EPL (10\%), increasing significantly but slightly the chroma. The amount of 468 EPL capable of migrate from the copolymer films to liquid medium was quantified revealing 469 that films possessing a lower percentage of ethylene released a greater amount of EPL. Bacterial 470 growth studies carried out at 37 and $4{ }^{\circ} \mathrm{C}$ with L. monocytogenes and E. coli in the presence of 471 the films incorporating EPL showed that a greater bacterial inhibition was achieved at $37{ }^{\circ} \mathrm{C}$ and 472 EVOH 29 were more effective than EVOH 44 films inhibiting bacterial growth. In vivo 473 experiments carried out with surimi sticks inoculated with pathogen bacteria and wrapped in 474 EVOH 29 and EVOH 44 with $10 \%$ of EPL, produced a reduction in the microbial load thus 475 increasing the microbiological shelf life of the product at refrigeration temperatures. Therefore, 476 the results obtained in this work provide strong evidence of the antimicrobial effect of active 477 EVOH films on the survival of L. monocytogenes and E. coli "in vitro" and inoculated into 478 surimi sticks stored under refrigeration temperatures. It was also concluded that $E$. coli was 
more resistant against EPL than L. monocytogenes. The present study shows that active

packaging is a non-thermal preservation technology which could be implemented to improve the microbiological stability of ready-to-eat surimi-derived products.

\section{ACKNOWLEDGEMENTS}

The authors acknowledge the financial support of the Spanish Ministry of Economy and Competitiveness, projects AGL2012-39920-C03-01, and fellowship funding for V. M.-G.

\section{REFERENCES}

Adams MR \& Moss MO (2008) Food Microbiology. The Royal Society of Chemistry Cambrigde, UK.

Aucejo S, Catala R \& Gavara R (2000) Interactions between water and EVOH food packaging films. Food Science and Technology International. 6(2), 159-164.

Brandt AL, Castillo A, Harris KB, Keeton JT, Hardin MD \& Taylor TM (2010) Inhibition of Listeria monocytogenes by Food Antimicrobials Applied Singly and in Combination. Journal of Food Science. 75(9), 557-563.

Buchanan RL \& Doyle MP (1997) Foodborne disease significance of Escherichia coli O157:H7 and other enterohemorrhagic E-coli. Food Technology. 51(10), 69-76.

Coton M, Denis C, Cadot P \& Coton E (2011) Biodiversity and characterization of aerobic spore-forming bacteria in surimi seafood products. Food Microbiology. 28(2), 252-260.

Chang S-S, Lu W-YW, Park S-H \& Kang D-H (2010) Control of foodborne pathogens on ready-to-eat roast beef slurry by epsilon-polylysine. International Journal of Food Microbiology. 141(3), 236-241.

Chang Y, McLandsborough L \& McClements DJ (2012) Cationic Antimicrobial (epsilonPolylysine)-Anionic Polysaccharide (Pectin) Interactions: Influence of Polymer Charge on Physical Stability and Antimicrobial Efficacy. Journal of Agricultural and Food Chemistry. 60(7), 1837-1844.

Chi-Zhang YD, Yam KL \& Chikindas ML (2004) Effective control of Listeria monocytogenes by combination of nisin formulated and slowly released into a broth system. International Journal of Food Microbiology. 90(1), 15-22.

FAO (2005) Further processing of fish. Fisheries and aquaculture department.

FDA (2004) Agency reponse letter GRAS Notice No. GRN 00135.

Gambarin P, Magnabosco C, Losio MN, Pavoni E, Gattuso A, Arcangeli G \& Favretti M (2012) Listeria monocytogenes in Ready-to-Eat Seafood and Potential Hazards for the Consumers. International Journal of Microbiology. 2012, 497635-497635.

Gunlu A \& Koyun E (2013) Effects of Vacuum Packaging and Wrapping with Chitosan-Based Edible Film on the Extension of the Shelf Life of Sea Bass (Dicentrarchus labrax) 
Fillets in Cold Storage (4 A degrees C). Food and Bioprocess Technology. 6(7), 17131719 .

Hiraki J (1995) Basic and applied studies on $\varepsilon$-polylysine. Journal of Antibacterial Antifungal Agents Japan. 23, 349-493.

Hiraki J (2000) ع-Polylysine, its development and utilization. Fine Chemistry. 29, 18-25.

Hiraki J, Ichikawa T, Ninomiya S, Seki H, Uohama K, Kimura S, Yanagimoto Y \& Barnett JW (2003) Use of ADME studies to confirm the safety of epsilon-polylysine as a preservative in food. Regulatory Toxicology and Pharmacology. 37(2), 328-340.

Ho YT, Ishizaki S \& Tanaka M (2000) Improving emulsifying activity of epsilon-polylysine by conjugation with dextran through the Maillard reaction. Food Chemistry. 68(4), 449455 .

Huss HH, Jorgensen LV \& Vogel BF (2000) Control options for Listeria monocytogenes in seafoods. International Journal of Food Microbiology. 62(3), 267-274.

Kaneko K, Hayashidani H, Ohtomo Y, Kosuge J, Kato M, Takahashi K, Shiraki Y \& Ogawa M (1999) Bacterial contamination of ready-to-eat foods and fresh products in retail shops and food factories. Journal of Food Protection. 62(6), 644-649.

Kang ET, Tan KL, Kato K, Uyama Y \& Ikada Y (1996) Surface modification and functionalization of polytetrafluoroethylene films. Macromolecules. 29(21), 6872-6879.

Li J, Han Q, Chen W \& Ye L (2012) Antimicrobial activity of Chinese bayberry extract for the preservation of surimi. Journal of the Science of Food and Agriculture. 92(11), 23582365.

Lopez-de-Dicastillo C, Alonso JM, Catala R, Gavara R \& Hernandez-Munoz P (2010) Improving the Antioxidant Protection of Packaged Food by Incorporating Natural Flavonoids into Ethylene-Vinyl Alcohol Copolymer (EVOH) Films. Journal of Agricultural and Food Chemistry. 58(20), 10958-10964.

Lopez-de-Dicastillo C, Pezo D, Nerin C, Lopez-Carballo G, Catala R, Gavara R \& HernandezMunoz P (2012) Reducing Oxidation of Foods Through Antioxidant Active Packaging Based on Ethyl Vinyl Alcohol and Natural Flavonoids. Packaging Technology and Science. 25(8), 457-466.

Lopez de Dicastillo C, Nerin C, Alfaro P, Catala R, Gavara R \& Hernandez-Munoz P (2011) Development of New Antioxidant Active Packaging Films Based on Ethylene Vinyl Alcohol Copolymer (EVOH) and Green Tea Extract. Journal of Agricultural and Food Chemistry. 59(14), 7832-7840.

M100-S18 (2008) Performance Standards for Antimicrobial Susceptibility Testing: Eighteenth Informational Supplement.

Mead PS \& Griffin PM (1998) Escherichia coli O157:H7. Lancet. 352(9135), 1207-1212.

Miya S, Takahashi H, Ishikawa T, Fujii T \& Kimura B (2010) Risk of Listeria monocytogenes Contamination of Raw Ready-To-Eat Seafood Products Available at Retail Outlets in Japan. Applied and Environmental Microbiology. 76(10), 3383-3386. 
Muriel-Galet V, Cerisuelo JP, Lopez-Carballo G, Aucejo S, Gavara R \& Hernandez-Munoz P (2013a) Evaluation of EVOH-coated PP films with oregano essential oil and citral to improve the shelf-life of packaged salad. Food Control. 30(1), 137-143.

Muriel-Galet V, Cerisuelo JP, Lopez-Carballo G, Lara M, Gavara R \& Hernandez-Munoz P (2012a) Development of antimicrobial films for microbiological control of packaged salad. International Journal of Food Microbiology. 157(2), 195-201.

Muriel-Galet V, Lopez-Carballo G, Gavara R \& Hernandez-Munoz P (2012b) Antimicrobial food packaging film based on the release of LAE from EVOH. International Journal of Food Microbiology. 157(2), 239-244.

Muriel-Galet V, López-Carballo G, Hernández-Muñoz P \& Gavara R (2013b) Characterization of ethylene-vinyl alcohol copolymer containing lauril arginate (LAE) as material for active antimicrobial food packaging. Food Packaging and Shelf Life. 1, 10-17.

Park JW (2014) Surimi and surimi seafood. CRC Press, Boca Raton, FL

Shima S, Matsuoka H, Iwamoto T \& Sakai H (1984) Antimicrobial action of epsilon-poly-Llysine. Journal of Antibiotics. 37(11), 1449-1455.

Shima S \& Sakai H (1977) Polylysine produced by Streptomyces. Agricultural and Biological Chemistry. 41(9), 1807-1809.

Singh RK \& Balange AK (2005) Characteristics of pink perch (Nemipterus japonicus) surimi at frozen temperature. Journal of Food Processing and Preservation. 29(1), 75-83.

Suppakul P, Miltz J, Sonneveld K \& Bigger SW (2003) Active packaging technologies with an emphasis on antimicrobial packaging and its applications. Journal of Food Science. 68(2), 408-420.

Ting HY, Ishizaki S \& Tanaka M (1999) Epsilon-polylysine improves the quality of surimi products. Journal of Muscle Foods. 10(4), 279-294.

Tzschoppe M, Martin A \& Beutin L (2012) A rapid procedure for the detection and isolation of enterohaemorrhagic Escherichia coli (EHEC) serogroup O26, O103, O111, O118, O121, O145 and O157 strains and the aggregative EHEC O104:H4 strain from readyto-eat vegetables. International Journal of Food Microbiology. 152(1-2), 19-30.

Uchida E, Uyama Y \& Ikada Y (1993) Sorption of Low-molecular-weight anions into thin polycation layers grafted onto a film. Langmuir. 9(4), 1121-1124.

Unalan IU, Ucar KDA, Arcan I, Korel F \& Yemenicioglu A (2011) Antimicrobial Potential of Polylysine in Edible Films. Food Science and Technology Research. 17(4), 375-380.

Venugopal V \& Shahidi F (1995) Value-added products from underutilized fish species. Critical Reviews in Food Science and Nutrition. 35(5), 431-453.

Zambuchini B, Fiorini D, Verdenelli MC, Orpianesi C \& Ballini R (2008) Inhibition of microbiological activity during sole (Solea solea L.) chilled storage by applying ellagic and ascorbic acids. LWT-Food Science and Technology. 41(9), 1733-1738.

Zinoviadou KG, Koutsoumanis KP \& Biliaderis CG (2010) Physical and thermo-mechanical properties of whey protein isolate films containing antimicrobials, and their effect against spoilage flora of fresh beef. Food Hydrocolloids. 24(1), 49-59. 


\section{LEGENDS TO FIGURES}

637

638 Fig.1. Scanning electron micrographs of L. monocytogenes cell A) CONTROL and B) 10\% 639 EPL. E. coli cell C) CONTROL and D) 10\% EPL.

640

641 Fig. 2. Growth control study with EVOH 29 control, 1, 5 and 10\% EPL. A) L. monocytogenes at $37{ }^{\circ} \mathrm{C}$ 642 and B) E.coli at $37^{\circ} \mathrm{C}$.

643

644 Fig. 3. Growth control study with EVOH 44 control, 1,5 and $10 \%$ EPL. A) L. monocytogenes at $37{ }^{\circ} \mathrm{C}$ 645 and B) E. coli at $37^{\circ} \mathrm{C}$.

646

647 Fig. 4. Growth control study with EVOH 29 control, 1, 5 and 10\% EPL. A) L. monocytogenes at $4{ }^{\circ} \mathrm{C}$ and 648 B) E. coli at $4{ }^{\circ} \mathrm{C}$.

649

650 Fig. 5. Growth control study with EVOH 44 control, $1 \%, 5 \%$ and $10 \%$ EPL. A) L. monocytogenes at $4{ }^{\circ} \mathrm{C}$ 651 and B) E. coli at $4{ }^{\circ} \mathrm{C}$.

652

653 Fig. 6. Antimicrobial activity of EVOH 29 films with 10\% EPL on surimi sticks inoculated with 654 (A) L. monocytogenes and (B) E. coli.

655

656 Fig. 7. Antimicrobial activity of EVOH 44 films with 10\% EPL on surimi sticks inoculated with 657 (A) L. monocytogenes and (B) E. coli. 
Click here to download high resolution image

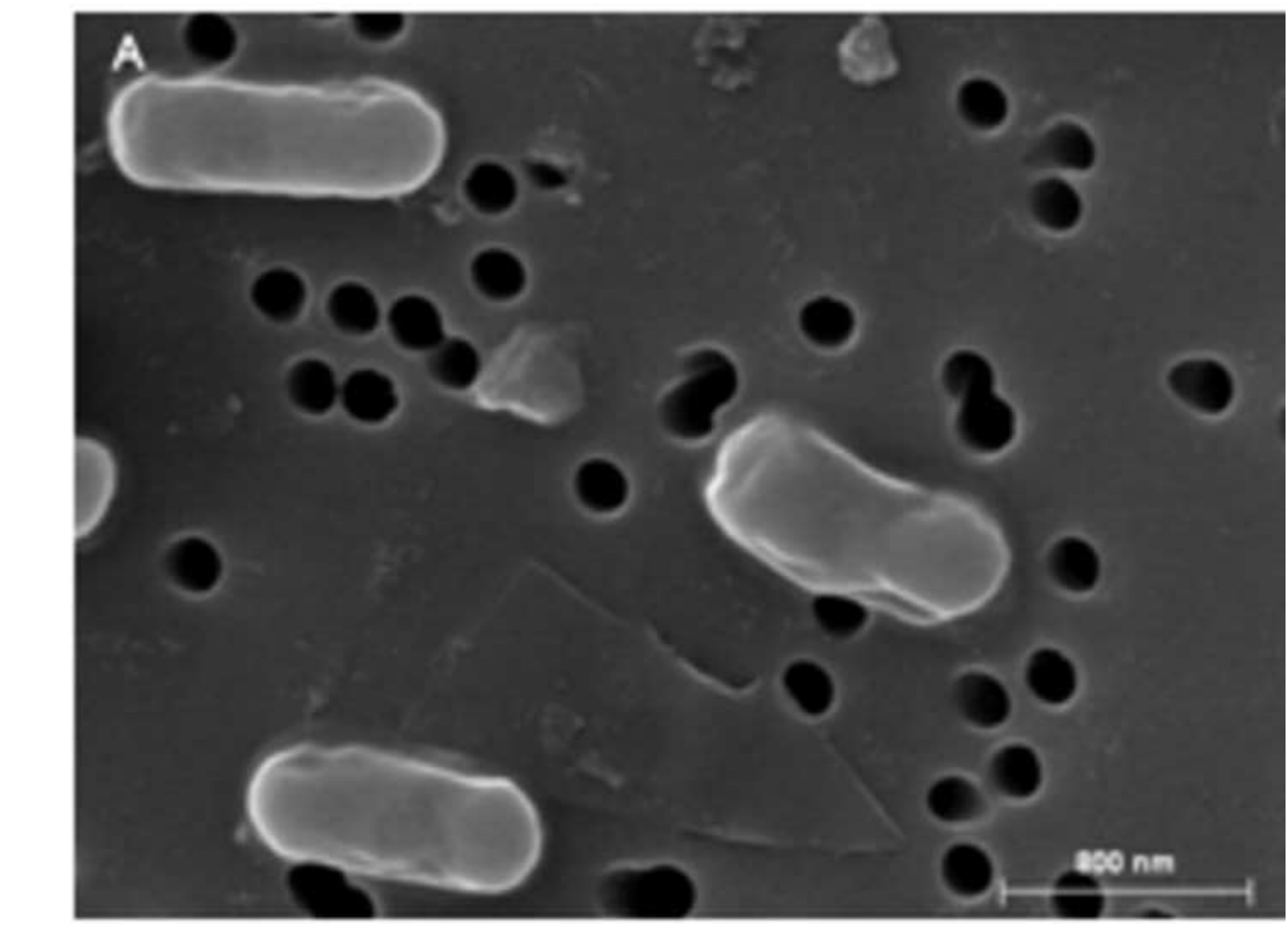

\section{re to}



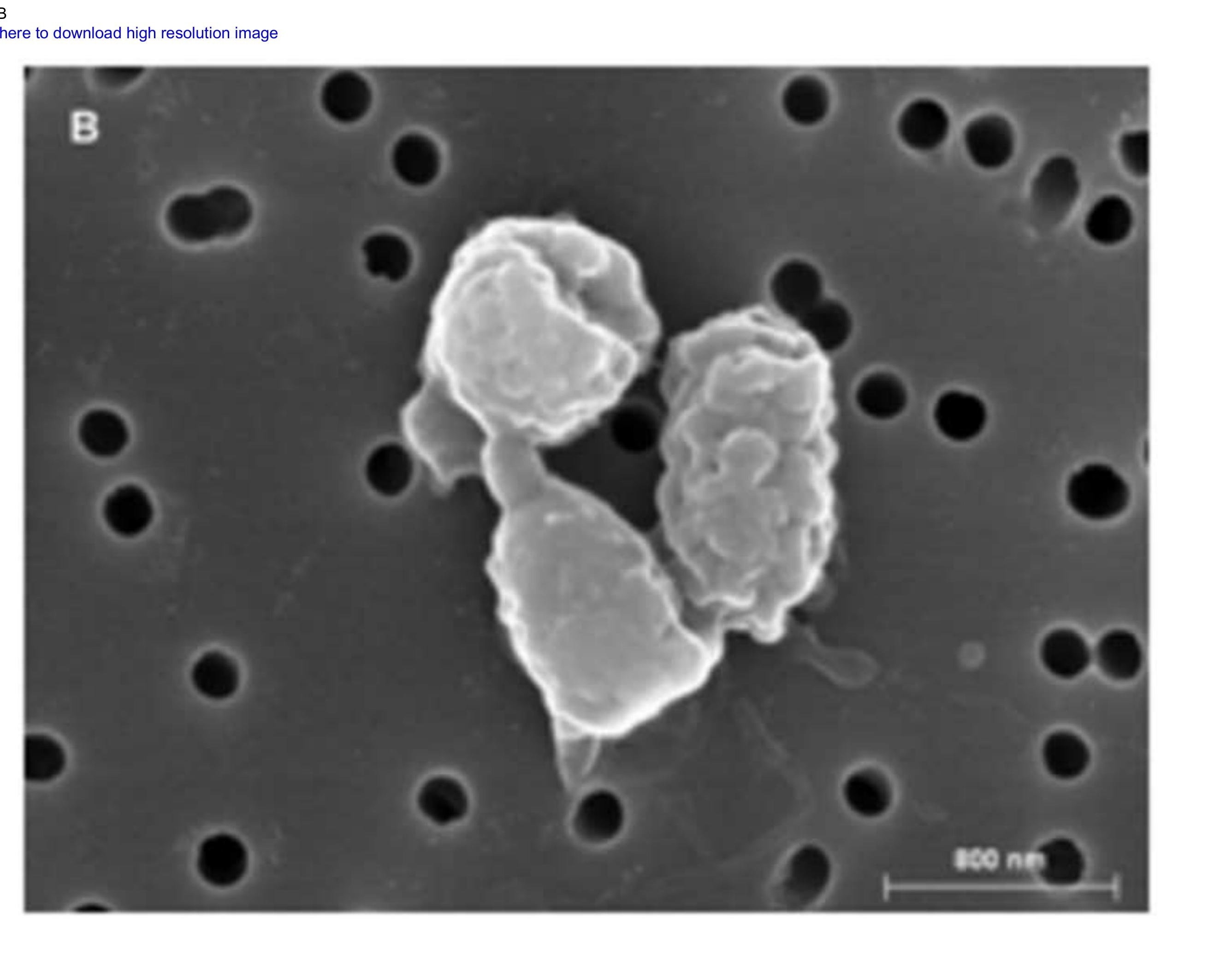


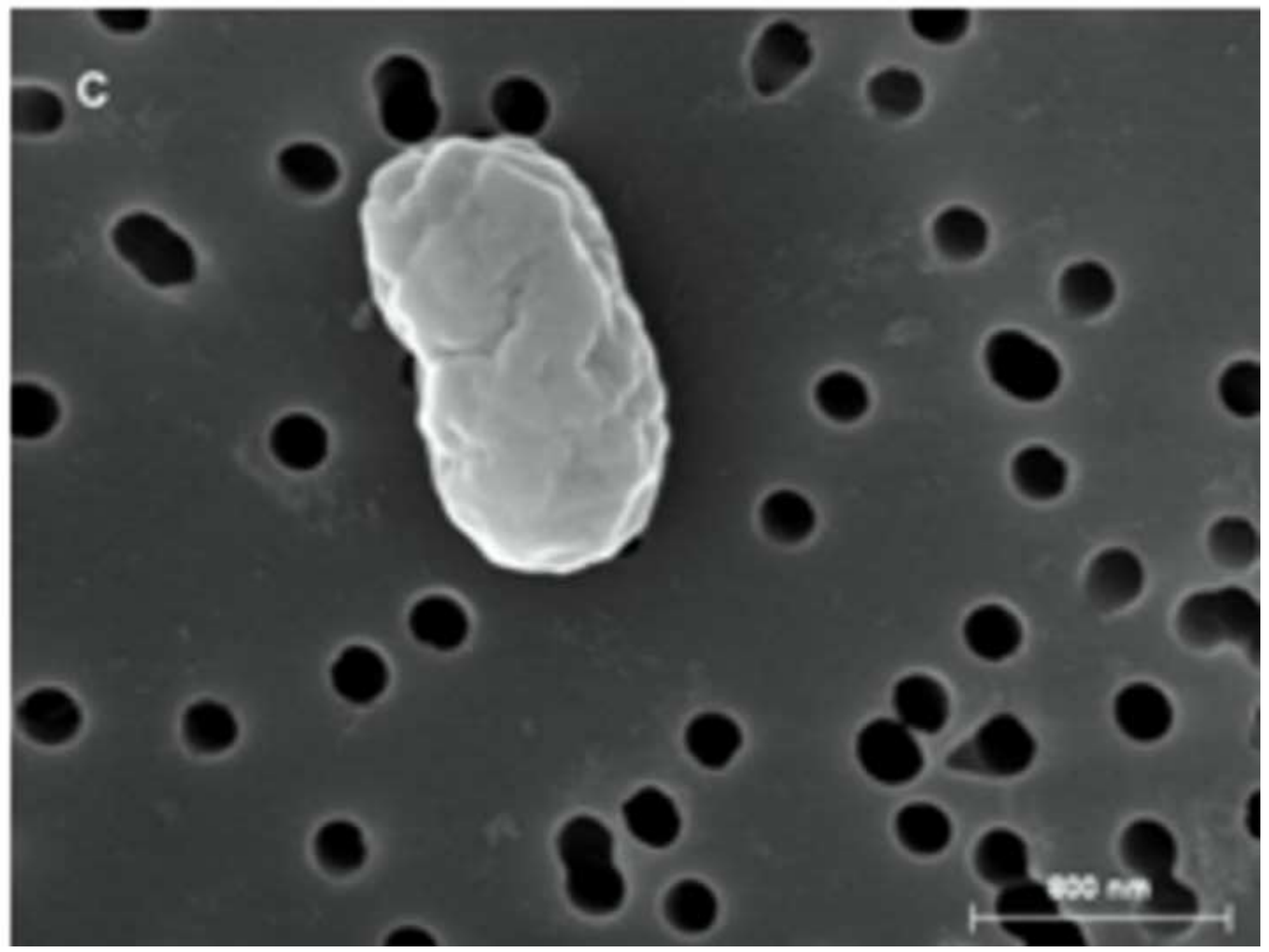


A

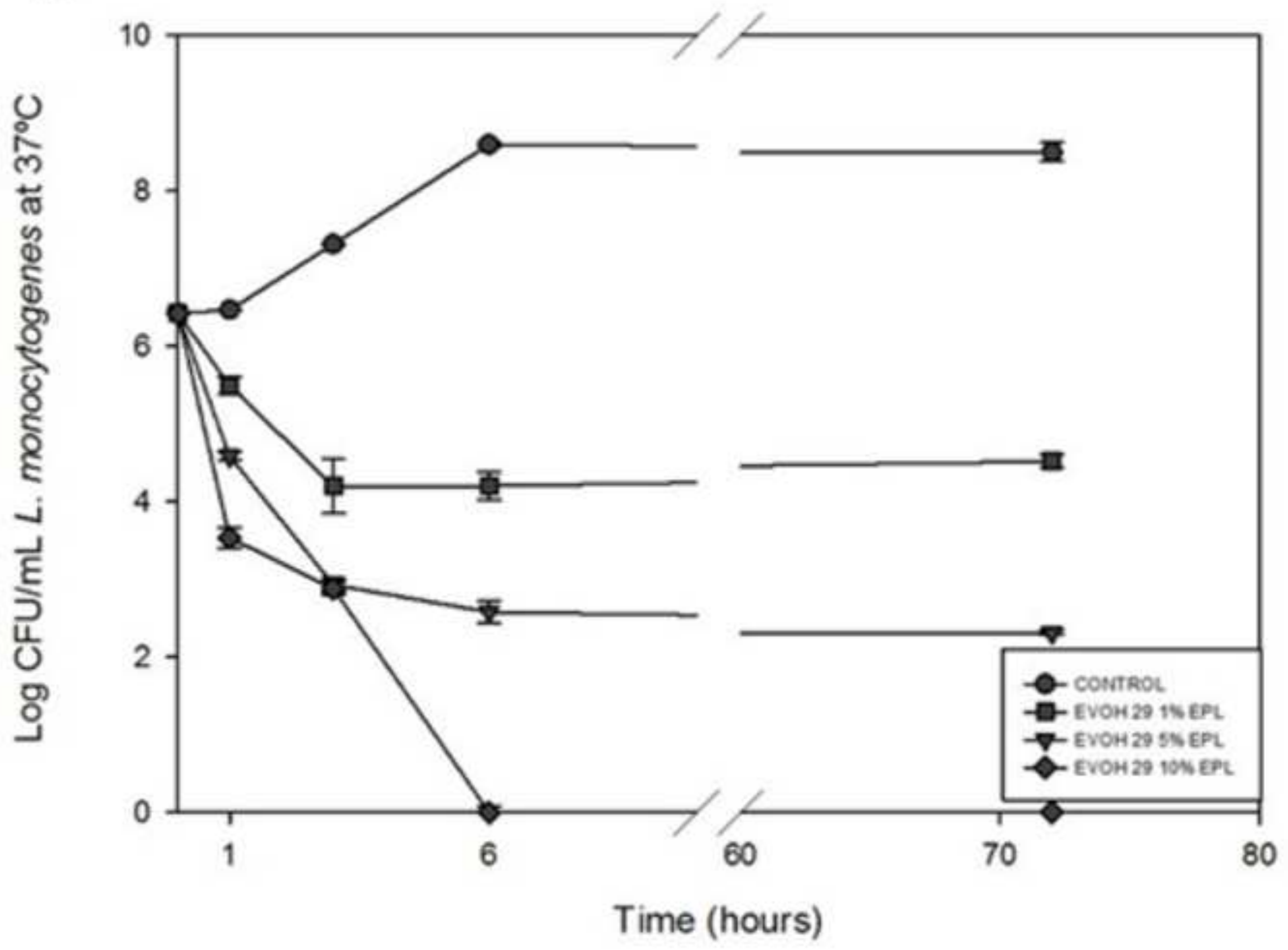


B

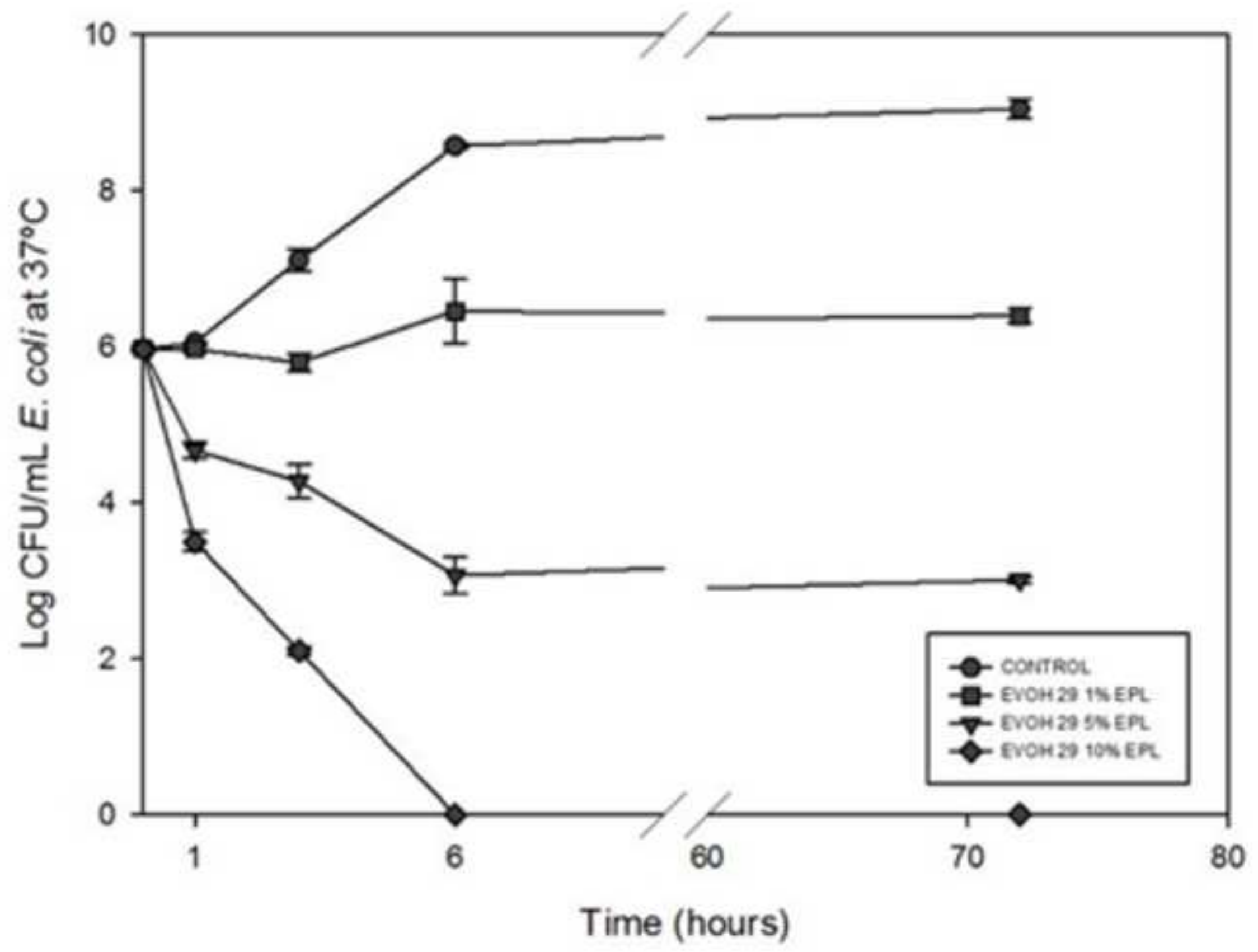


A

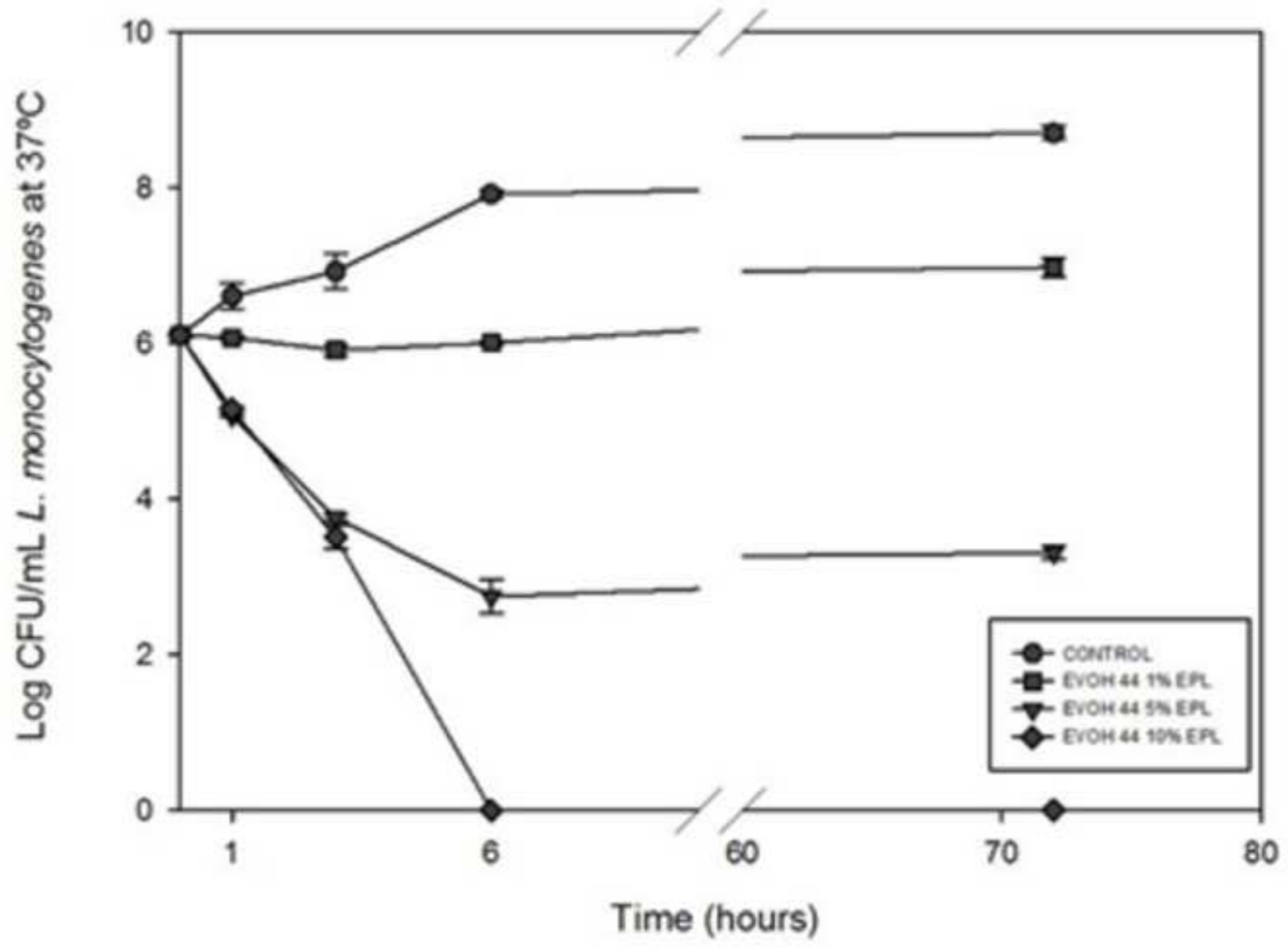


Fig-3B
Click here to download high resolution image

B

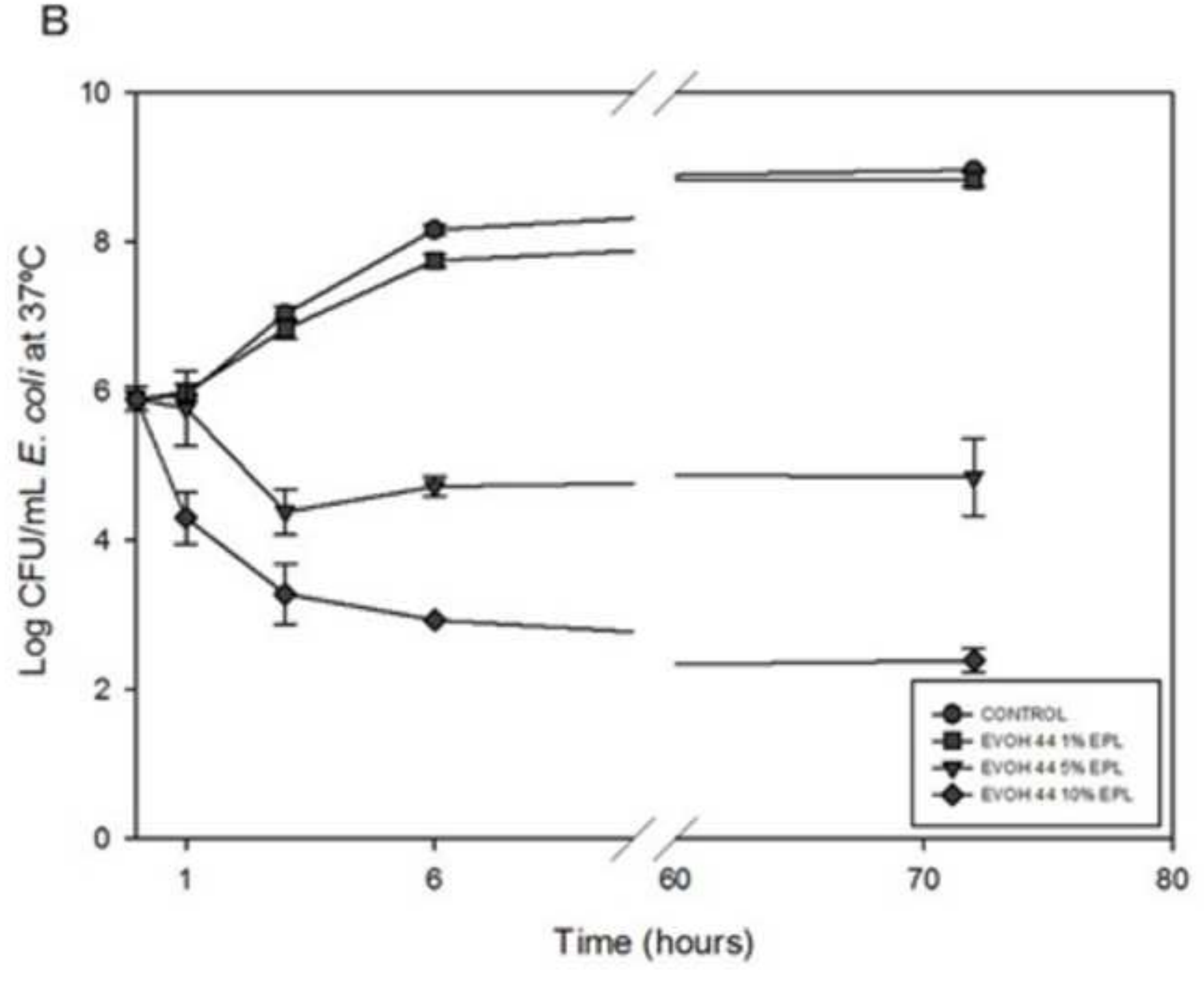

Click here to down load high resolution image

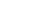

.

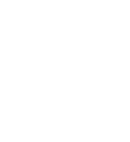


A

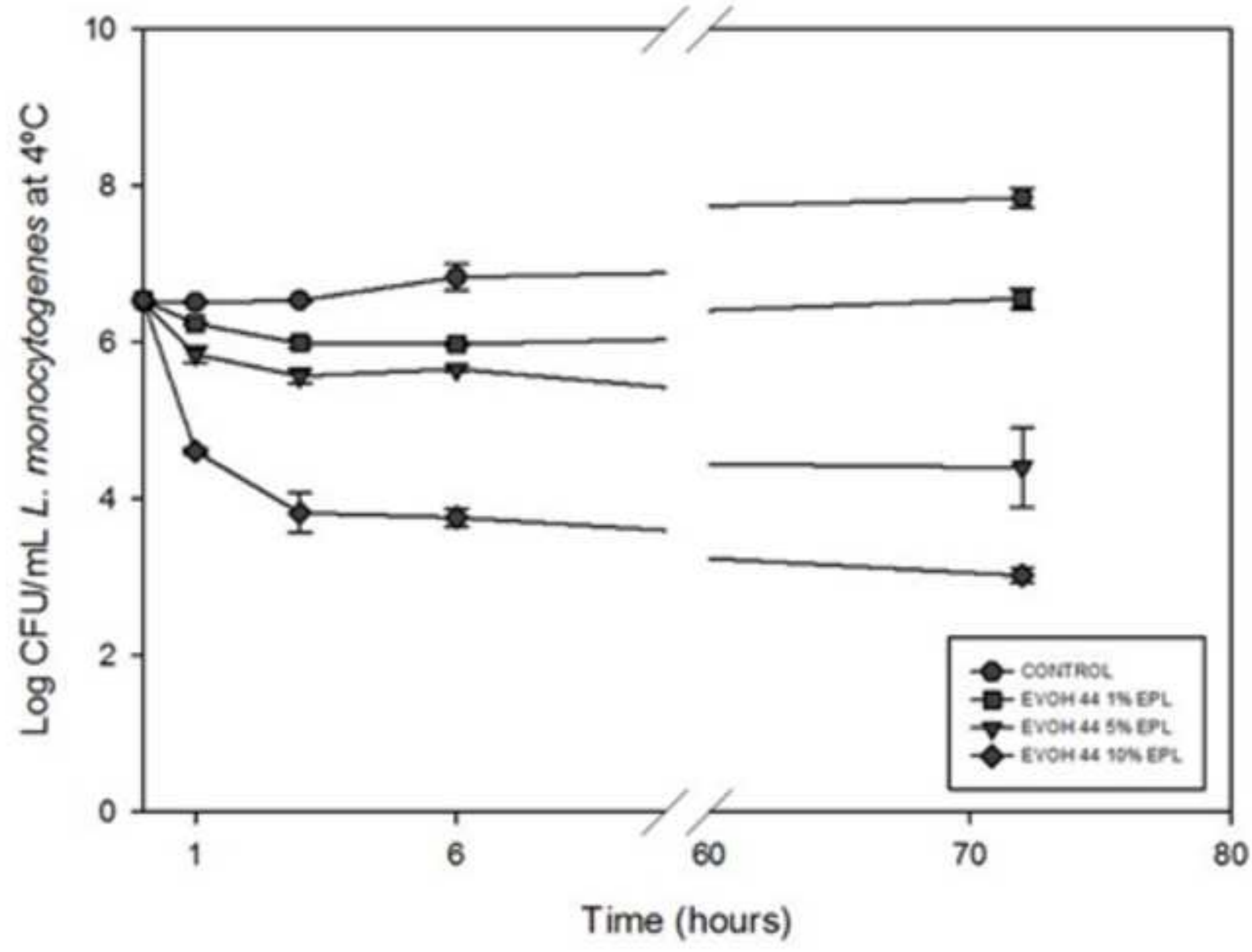


Click here to download high resolution image

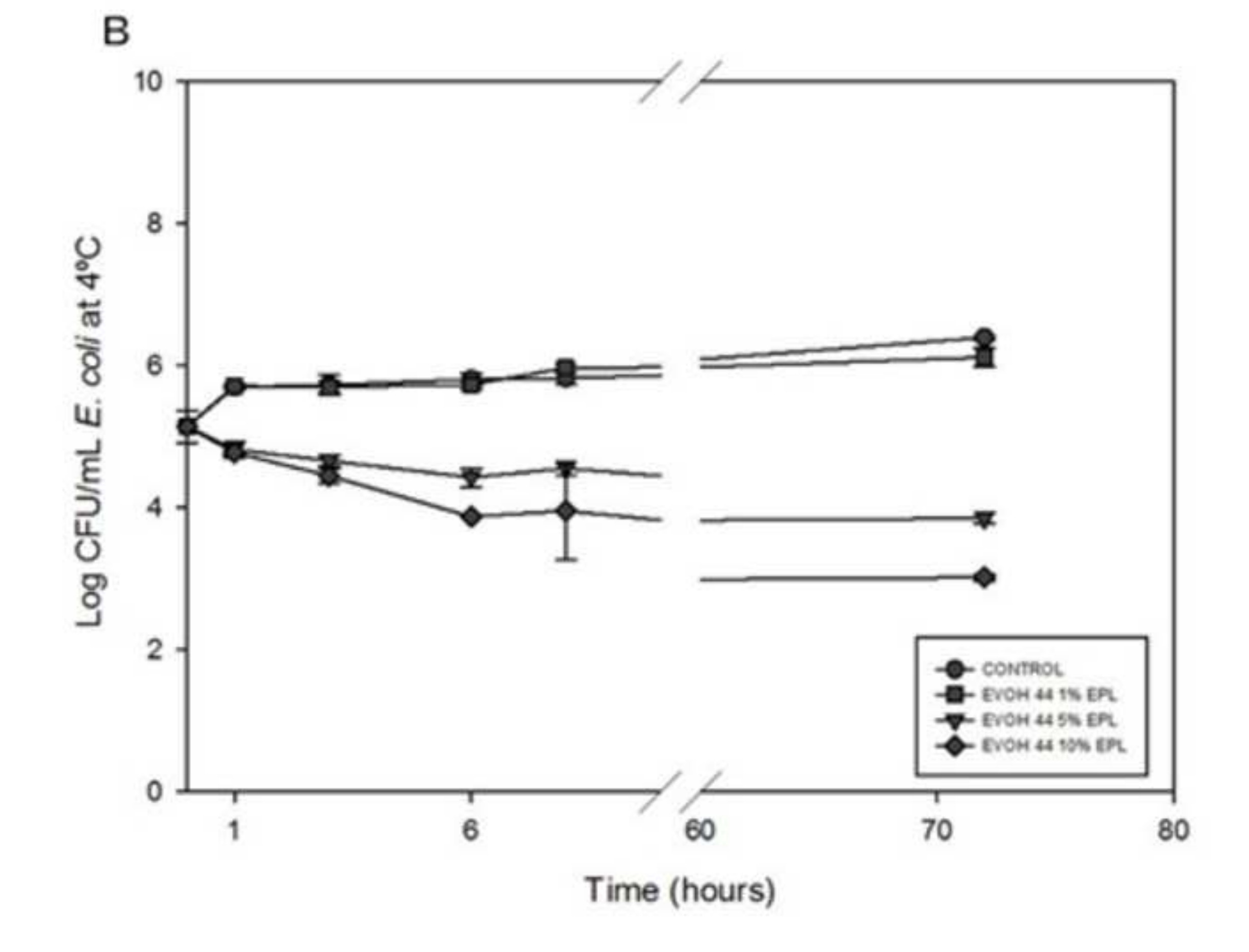

.

(n)


A

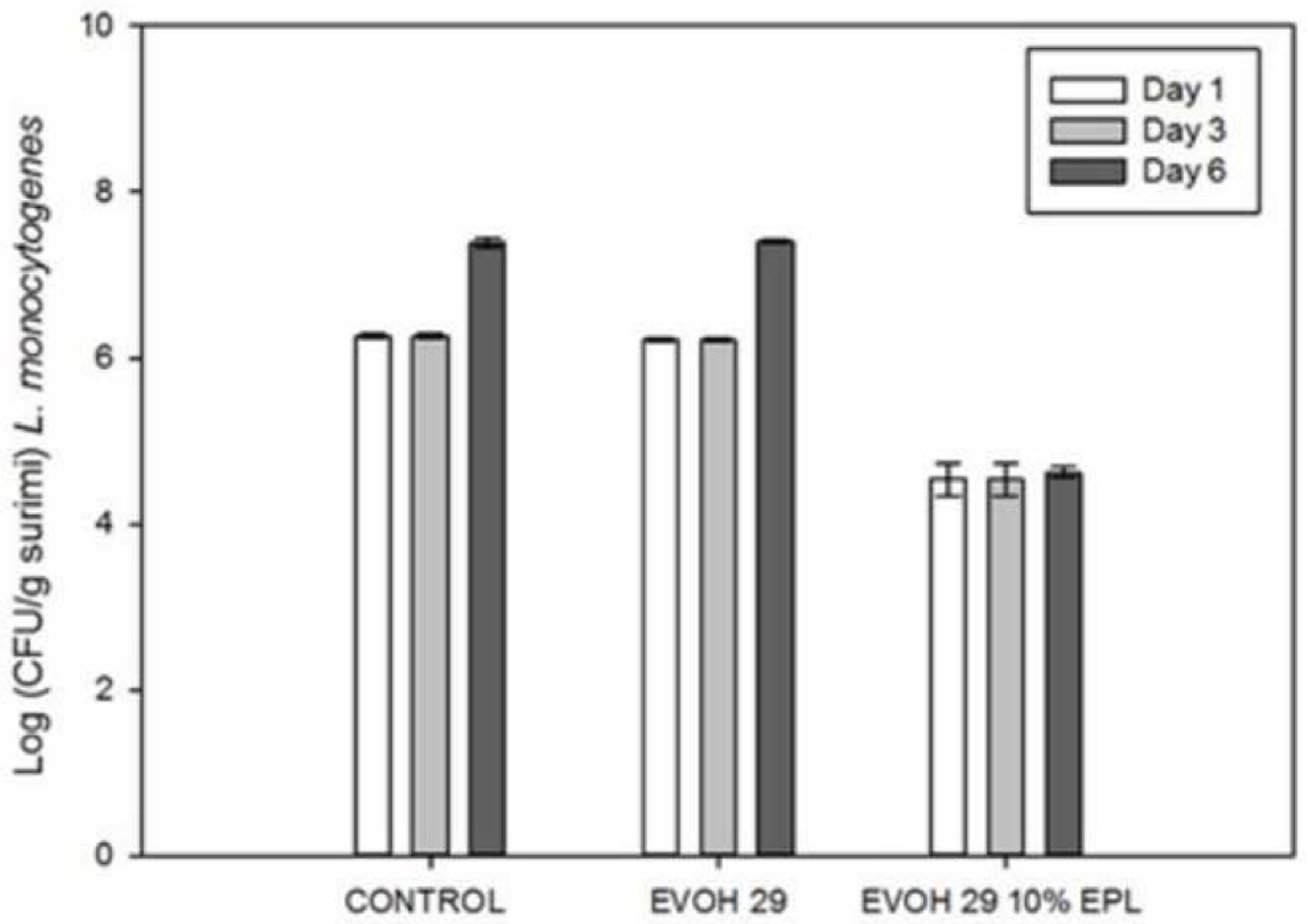


B

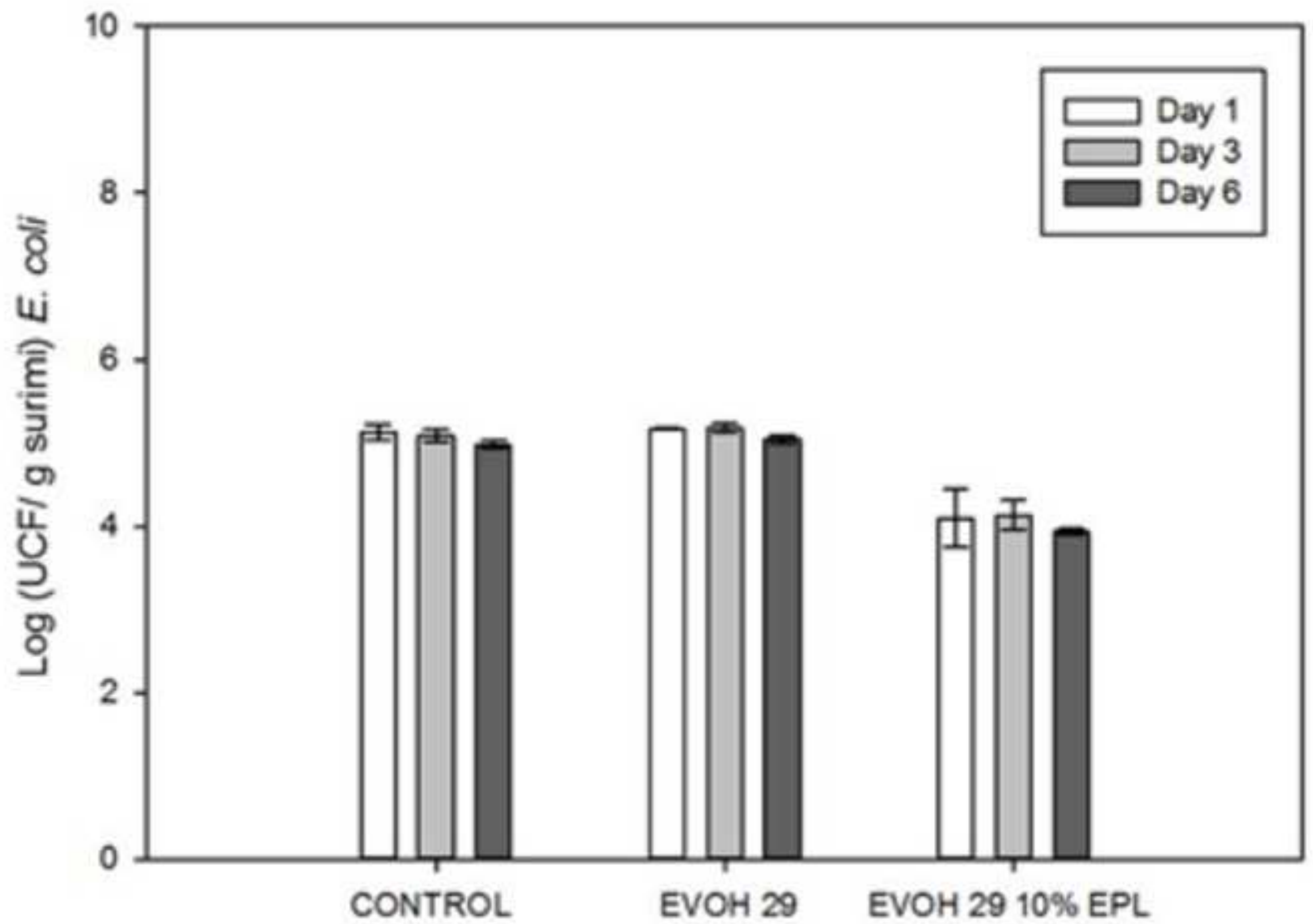


A

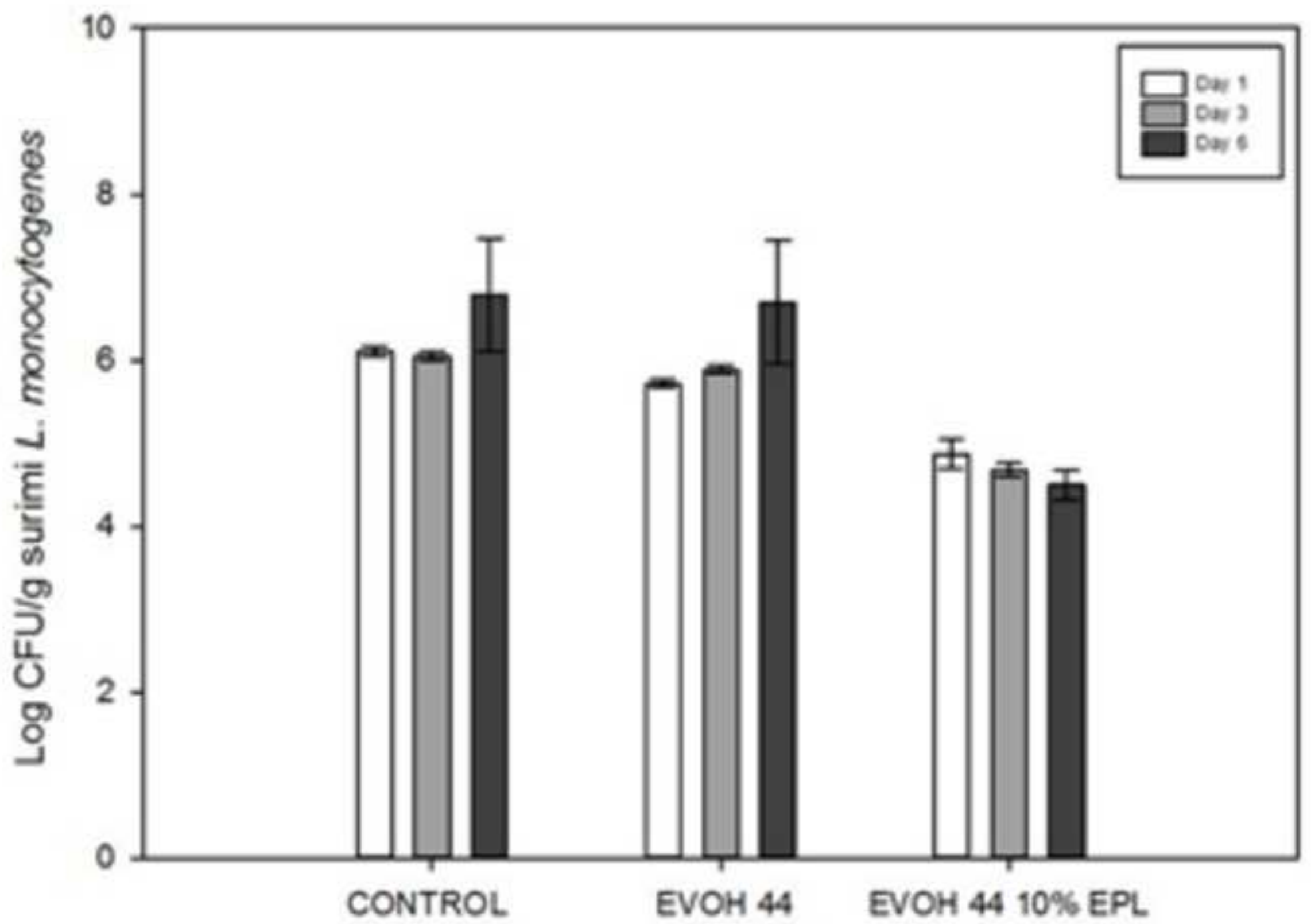


B

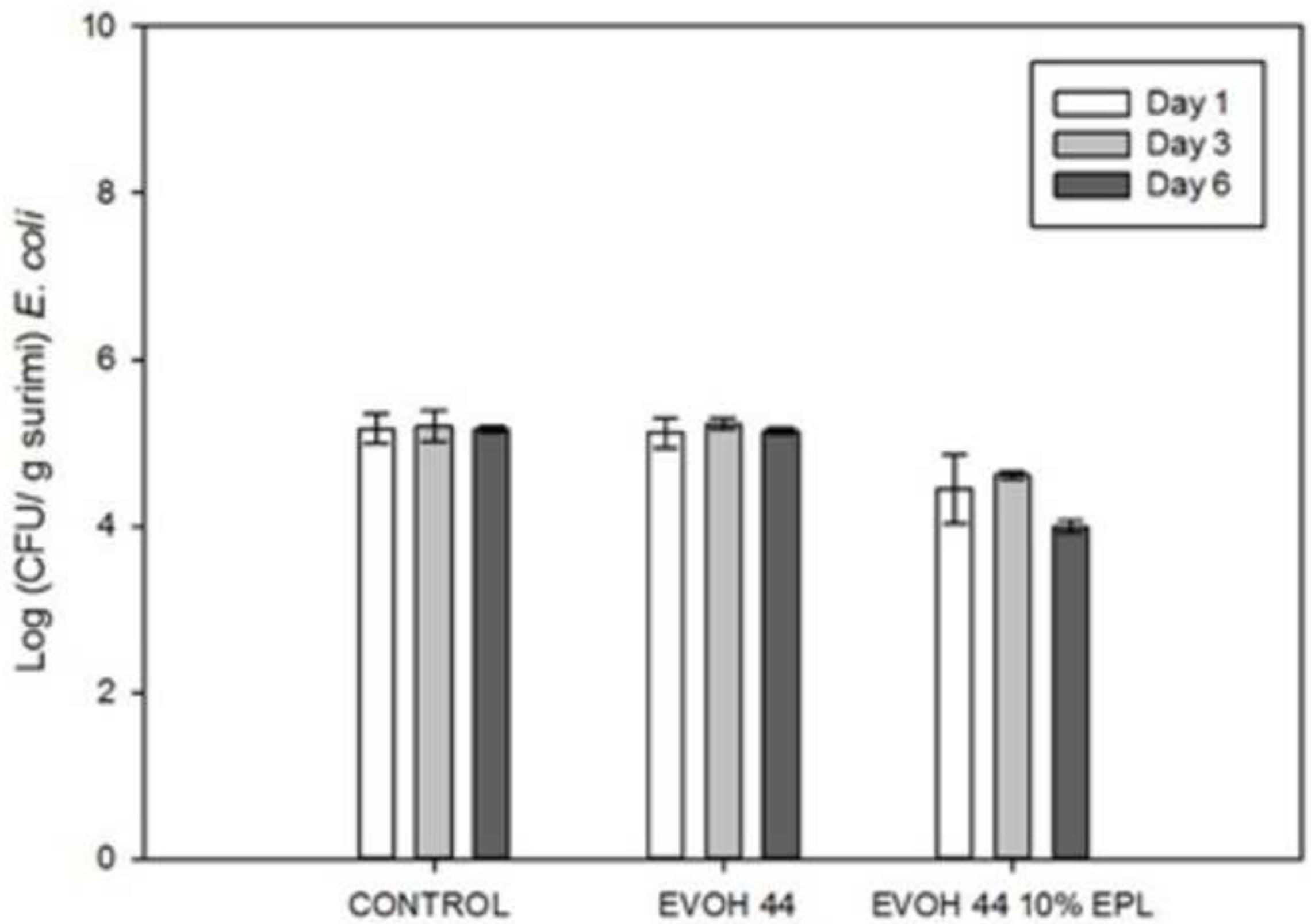


Table 1. Colour parameters of EVOH 29 and EVOH 44, without and with 1, 5 and 10\% of EPL.

\begin{tabular}{lccccc}
\hline EVOH 29 & $\mathbf{L}^{*}$ & $\mathbf{a}^{*}$ & $\mathbf{b}^{*}$ & $\mathbf{C}^{*}$ & $\mathbf{h}^{\mathbf{0}}$ \\
\hline CONTROL & $90.27 \pm 0.18^{\mathrm{a}}$ & $-0.86 \pm 0.02^{\mathrm{a}}$ & $1.09 \pm 0.04^{\mathrm{a}}$ & $1.39 \pm 0.02^{\mathrm{a}}$ & $128.22 \pm 1.65^{\mathrm{a}}$ \\
$1 \%$ EPL & $89.43 \pm 0.65^{\mathrm{a}}$ & $-0.89 \pm 0.02^{\mathrm{a}}$ & $1.13 \pm 0.10^{\mathrm{a}}$ & $1.44 \pm 0.08^{\mathrm{a}}$ & $128.41 \pm 2.64^{\mathrm{a}}$ \\
$5 \%$ EPL & $89.40 \pm 0.70^{\mathrm{a}}$ & $-0.93 \pm 0.04^{\mathrm{a}}$ & $1.13 \pm 0.08^{\mathrm{a}}$ & $1.47 \pm 0.04^{\mathrm{a}}$ & $129.49 \pm 3.04^{\mathrm{a}}$ \\
$10 \%$ EPL & $89.84 \pm 0.43^{\mathrm{a}}$ & $-0.97 \pm 0.02^{\mathrm{b}}$ & $1.30 \pm 0.04^{\mathrm{b}}$ & $1.62 \pm 0.02^{\mathrm{b}}$ & $129.82 \pm 1.53^{\mathrm{a}}$ \\
\hline
\end{tabular}

\begin{tabular}{lccccc}
\hline EVOH 44 & $\mathbf{L}^{*}$ & $\mathbf{a}^{*}$ & $\mathbf{b}^{*}$ & $\mathbf{C}^{*}$ & $\mathbf{h}^{\mathbf{o}}$ \\
\hline CONTROL & $89.82 \pm 0.97^{\mathrm{a}}$ & $-0.88 \pm 0.05^{\mathrm{a}}$ & $1.02 \pm 0.12^{\mathrm{a}}$ & $1.35 \pm 0.07^{\mathrm{a}}$ & $129.12 \pm 4.34^{\mathrm{a}}$ \\
$1 \%$ EPL & $89.98 \pm 0.53^{\mathrm{a}}$ & $-0.86 \pm 0.06^{\mathrm{a}}$ & $1.07 \pm 0.08^{\mathrm{a}}$ & $1.38 \pm 0.08^{\mathrm{a}}$ & $128.86 \pm 2.59^{\mathrm{a}}$ \\
$5 \%$ EPL & $89.80 \pm 0.67^{\mathrm{a}}$ & $-0.89 \pm 0.04^{\mathrm{a}}$ & $1.16 \pm 0.08^{\mathrm{b}}$ & $1.47 \pm 0.05^{\mathrm{b}}$ & $127.42 \pm 2.83^{\mathrm{a}}$ \\
$10 \%$ EPL & $90.21 \pm 0.66^{\mathrm{a}}$ & $-0.98 \pm 0.06^{\mathrm{b}}$ & $1.24 \pm 0.09^{\mathrm{b}}$ & $1.57 \pm 0.10^{\mathrm{b}}$ & $127.55 \pm 0.95^{\mathrm{a}}$ \\
\hline
\end{tabular}

${ }^{\mathrm{a}-\mathrm{c}}$ Different letters in the same column indicate significant differences among the values of the color parameter of each $\mathrm{EVOH}$ copolymer (Turkey's adjusted analysis of variance, $\mathrm{P}<0.05$ ). 
Table 2. EPL migrated from EVOH films to phosphate buffer $\mathrm{pH} 7.5$ at $37{ }^{\circ} \mathrm{C}$ after 24 hours.

\begin{tabular}{|c|c|c|c|c|}
\hline $\begin{array}{c}\text { EPL in EVOH } \\
(\%)\end{array}$ & $\begin{array}{c}\text { From EVOH } 29 \\
(\mu \mathrm{g} / \mathrm{mL})\end{array}$ & Migration (\%) & $\begin{array}{c}\text { From EVOH } 44 \\
(\mu \mathrm{g} / \mathrm{mL})\end{array}$ & Migration (\%) \\
\hline $1 \%$ EPL & $47.43 \pm 0.02^{\mathrm{a}}$ & 18.97 & $42.87 \pm 0.01^{\mathrm{a}}$ & 17.15 \\
\hline $5 \%$ EPL & $68.19 \pm 0.02^{\mathrm{b}}$ & 5.45 & $58.82 \pm 0.01^{\mathrm{b}}$ & 4.71 \\
\hline $10 \%$ EPL & $95.90 \pm 0.03^{\mathrm{c}}$ & 3.84 & $71.46 \pm 0.03^{\mathrm{c}}$ & 2.86 \\
\hline
\end{tabular}
medium (Turkey's adjusted analysis of variance, $\mathrm{P}<0.05$ ). 
Table 3. Antimicrobial effectiveness of EVOH 29 films against $L$. monocytogenes and $E$. coli at $37{ }^{\circ} \mathrm{C}$ expressed as logarithm of colony forming units per $\mathrm{mL}(\mathrm{Log}(\mathrm{CFU} / \mathrm{mL}))$ and logarithm reduction value (LRV).

\begin{tabular}{lcccc}
\hline \multicolumn{4}{c}{ L. monocytogenes } & \multicolumn{2}{c}{ E. coli } \\
\hline & \multicolumn{1}{c}{ Log $(\mathbf{C F U} / \mathbf{m L})$} & LRV & $\left.9.08 \pm 0.02^{\mathrm{c}}\right)$ & LRV \\
\hline CONTROL & $8.49 \pm 0.08^{\mathrm{c}}$ & & $6.34 \pm 0.12^{\mathrm{b}}$ & 2.74 \\
EVOH 29 1\% EPL & $4.40 \pm 0.12^{\mathrm{b}}$ & 4.09 & $3.50 \pm 0.12^{\mathrm{a}}$ & 5.58 \\
EVOH 29 5\% EPL & $2.40 \pm 0.09^{\mathrm{a}}$ & 6.09 & Total inhibition & 8.49 \\
EVOH 29 10\% EPL & Total inhibition & 8.49 & &
\end{tabular}

${ }^{\mathrm{a}-\mathrm{c}}$ Different letters in the same column indicate significant differences in antimicrobial effectiveness of different EVOH 29 films (Turkey's adjusted analysis of variance, $\mathrm{P}<0.05$ ). 
Table 4. Antimicrobial effectiveness of EVOH 44 films against L. monocytogenes and E. coli at $37^{\circ} \mathrm{C}$ expressed as logarithm of colony forming units $(\mathrm{Log}(\mathrm{CFU} / \mathrm{mL}))$ and $\log$ reduction value (LRV).

\begin{tabular}{lcccc}
\hline & \multicolumn{2}{c}{ L. monocytogenes } & \multicolumn{2}{c}{ E. coli } \\
\hline & Log(CFU/mL) & LRV & Log(CFU/mL) & LRV \\
\hline CONTROL & $8.15 \pm 0.06^{\mathrm{c}}$ & & $8.86 \pm 0.07^{\mathrm{c}}$ & \\
EVOH 44 1\% EPL & $6.76 \pm 0.03^{\mathrm{b}}$ & 1.39 & $8.34 \pm 0.15^{\mathrm{c}}$ & 0.52 \\
EVOH 44 5\% EPL & $3.18 \pm 0.01^{\mathrm{a}}$ & 4.97 & $4.92 \pm 0.09^{\mathrm{b}}$ & 3.94 \\
EVOH 44 10\% EPL & Total inhibition $^{\mathrm{a}-\mathrm{c}}$ Differ & 8.15 & $2.22 \pm 0.19^{\mathrm{a}}$ & 6.64 \\
\hline
\end{tabular}

${ }^{\mathrm{a}-\mathrm{c}}$ Different letters in the same column indicate significant differences in antimicrobial effectiveness of different EVOH 44 films (Turkey's adjusted analysis of variance, $\mathrm{P}<0.05$ ). 
Table 5. Enumeration of microbial population in surimi: Lactic acid bacteria, Psychrotrophic bacteria, Total aerobic count and Pseudomonas expressed as logarithm of colony forming units per $\mathrm{g}(\mathrm{Log}(\mathrm{CFU} / \mathrm{g}))$ and logarithm reduction value (LRV).

\begin{tabular}{|c|c|c|c|c|}
\hline & \multicolumn{2}{|c|}{ Day 3} & \multicolumn{2}{|c|}{ Day 6} \\
\hline & $\log (\mathrm{CFU} / \mathrm{g})$ & LRV & $\log (\mathrm{CFU} / \mathrm{g})$ & LRV \\
\hline \multicolumn{5}{|l|}{ Lactic acid bacteria } \\
\hline CONTROL & $3.45 \pm 0.23$ & & $3.89 \pm 0.15$ & \\
\hline EVOH $2910 \%$ EPL & Total inhibition & 3.45 & Total inhibition & 3.89 \\
\hline EVOH 44 10\% EPL & Total inhibition & 3.45 & Total inhibition & 3.89 \\
\hline \multicolumn{5}{|l|}{ Psychrotrophic bacteria } \\
\hline CONTROL & $3.09 \pm 0.14^{b}$ & & $5.00 \pm 0.13^{b}$ & \\
\hline EVOH $2910 \%$ EPL & $1.64 \pm 0.61^{\mathrm{a}}$ & 1.45 & $2.84 \pm 0.11^{\mathrm{a}}$ & 2.16 \\
\hline EVOH 44 10\% EPL & $2.02 \pm 0.37^{\mathrm{a}}$ & 1.07 & $3.29 \pm 0.09^{\mathrm{a}}$ & 1.71 \\
\hline \multicolumn{5}{|l|}{ Total aerobic count } \\
\hline CONTROL & $2.34 \pm 0.06$ & & $3.18 \pm 0.02^{\mathrm{b}}$ & \\
\hline EVOH $2910 \%$ EPL & Total inhibition & 2.34 & Total inhibition & 3.18 \\
\hline EVOH $4410 \%$ EPL & Total inhibition & 2.34 & $1.90 \pm 0.24^{\mathrm{a}}$ & 1.28 \\
\hline \multicolumn{5}{|l|}{ Pseudomonas } \\
\hline CONTROL & $3.04 \pm 0.12^{\mathrm{b}}$ & & $3.63 \pm 0.03^{b}$ & \\
\hline EVOH $2910 \%$ EPL & Total inhibition & 3.04 & $2.20 \pm 0.10^{\mathrm{a}}$ & 1.43 \\
\hline EVOH $4410 \%$ EPL & $2.36 \pm 0.14^{\mathrm{a}}$ & 0.68 & $2.62 \pm 0.11^{\mathrm{a}}$ & 1.01 \\
\hline
\end{tabular}

${ }^{a-b}$ Different letters in the same column for each microorganisms indicate significant differences in antimicrobial effectiveness of different EVOH films (Turkey's adjusted analysis of variance, $\mathrm{P}<0.05$ ). 